\title{
Microglia-Induced Maladaptive Plasticity Can Be Modulated by Neuropeptides In Vivo
}

\author{
Stefano Morara, ${ }^{1,2}$ Anna Maria Colangelo, ${ }^{3,4,5}$ and Luciano Provini ${ }^{2}$ \\ ${ }^{1}$ Neuroscience Institute (CNR), Via Vanvitelli 32, 20129 Milano, Italy \\ ${ }^{2}$ Department of BIOMETRA, University of Milano, Via Vanvitelli 32, 20129 Milano, Italy \\ ${ }^{3}$ Laboratory of Neuroscience "R. Levi-Montalcini", Department of Biotechnology and Biosciences, University of Milano-Bicocca, \\ Piazza della Scienza 2, 20126 Milano, Italy \\ ${ }^{4}$ SYSBIO Centre of Systems Biology, University of Milano-Bicocca, Piazza della Scienza 2, 20126 Milano, Italy \\ ${ }^{5}$ NeuroMI Milan Center for Neuroscience, University of Milano-Bicocca, 20126 Milano, Italy \\ Correspondence should be addressed to Stefano Morara; stefano.morara@in.cnr.it
}

Received 27 March 2015; Accepted 25 June 2015

Academic Editor: Stuart C. Mangel

Copyright (c) 2015 Stefano Morara et al. This is an open access article distributed under the Creative Commons Attribution License, which permits unrestricted use, distribution, and reproduction in any medium, provided the original work is properly cited.

\begin{abstract}
Microglia-induced maladaptive plasticity is being recognized as a major cause of deleterious self-sustaining pathological processes that occur in neurodegenerative and neuroinflammatory diseases. Microglia, the primary homeostatic guardian of the central nervous system, exert critical functions both during development, in neural circuit reshaping, and during adult life, in the brain physiological and pathological surveillance. This delicate critical role can be disrupted by neural, but also peripheral, noxious stimuli that can prime microglia to become overreactive to a second noxious stimulus or worsen underlying pathological processes. Among regulators of microglia, neuropeptides can play a major role. Their receptors are widely expressed in microglial cells and neuropeptide challenge can potently influence microglial activity in vitro. More relevantly, this regulator activity has been assessed also in vivo, in experimental models of brain diseases. Neuropeptide action in the central nervous system has been associated with beneficial effects in neurodegenerative and neuroinflammatory pathological experimental models. This review describes some of the mechanisms of the microglia maladaptive plasticity in vivo and how neuropeptide activity can represent a useful therapeutical target in a variety of human brain pathologies.
\end{abstract}

\section{Introduction}

Inflammation developed as a defensive beneficial process that can protect from an external insult. In a simplistic manner, following infection or trauma a defensive barrier is created by the activation of specific cellular and molecular inflammatory mechanisms that kill pathogens or infected cells and eliminate dying/dead cells and clear debris while secreting cytokines and chemokines (among other factors) to orchestrate a multicellular response. This process is accomplished, in the periphery, by the array of immune cells that sense the danger, migrate, and recruit additional defenders to attack the intruders or protect tissues from damaged cells. When the defensive/reparative effect is achieved, the inflammatory response is dampened and finally resolved $[1$, 2]. Such homeostatic process requires both (i) a continuous surveillance of the environment performed by specialized cells that monitor changes and counteract any danger and (ii) the capacity to stop the defensive action (to resolve inflammation).

Chronic inflammation, instead, occurs when the resolving process fails and the defensive inflammatory cells trigger a self-sustained process that continues in the absence of underlying dangers, creating a new one. This constitutes what is now referred to as a maladaptive process and leads to a broken homeostatic equilibrium. To provide a few examples, this process is thought to occur in pulmonary hypertension [3], ischemic acute kidney injury [4], and coronary artery disease induced by atherosclerosis [5]. A classic example of maladaptive response is allergic asthma that can occur following repeated exposure to allergenic or viral agents during infancy [6]. Allergic asthma is thought to be driven 
by altered responses of Th2 and Th17 lymphocytes (but also type- 2 innate lymphoid cells) with the intervention of specific molecular pathways involving complement cascade components and a fibrinogen/proteinases/toll-like receptor (TLR) sequence [7-10].

It is worth mentioning that among immune cells macrophages (the peripheral counterparts of microglia) have been claimed to be involved in maladaptive responses. For example, cardiac interstitial fibrosis is exacerbated after myocardial infarction by caveolin-1 deletion that promotes an unbalanced M2 macrophage activation [11], whereas altered lipid metabolism and accumulation of cholesterol-laden macrophages in the artery wall cause a chronic inflammation leading to atherosclerosis [12].

\section{Brain: Homeostasis and Maladaptive Responses}

Homeostasis is needed within the central nervous system (CNS) also. The specificity of the structures and mechanisms that sustain CNS functioning requires a tightly controlled, delicate balance in and around neuronal and glial cells. The rapid and continuous exchanges of patrolling immune cells must be avoided in the brain under physiological conditions (or at least reduced at a much lower level than the one attained in the periphery): such avoidance has been accomplished through what is referred to as "immuneprivilege/specialization" of the brain, which implies, for example, the relative inaccessibility to the brain parenchyma by the peripheral immune cells (see, however, the detailed discussions in $[13,14])$. The brain homeostasis is thus tightly regulated by specific resident effectors, the main one being microglia.

Microglia are emerging as crucial players in brain functioning (and development) [15] and the number of papers reporting on them has increased exponentially during the last few years. They are the primary immune cells in the CNS and have been historically classified in morphological and functional terms as subdivided in three different forms, the ramified-resting, the bushy-activated, and the ameboid, macrophage-like, phagocyting form [15]. A major breakthrough about their primarily immunological/inflammatory role came from time-lapse two-photon imaging experiments that showed that the fine processes and protrusions of ramified/resting microglial cells are extremely motile in the intact mouse cortex and continually survey their microenvironment $[16,17]$. Following focal traumatic brain injury the processes rapidly converge on the site of injury (without cell body movements) and shield the healthy tissue from the injured one $[16,17]$. Subsequently, the same technical approach allowed discovering that fine microglial processes make direct contacts with neuronal synapses that in the intact brain are retracted within a time scale of a few minutes, whereas, following transient cerebral ischemia, they are kept for much longer time (about one hour) and are frequently followed by the disappearance of the presynaptic terminal [18]. Soon after that, another major breakthrough was the demonstration that the physiologically occurring synaptic pruning during postnatal development requires the active involvement of microglia that phagocyte synaptic material: this process is mediated by the fractalkine receptor $\mathrm{Cx} 3 \mathrm{crl}$ and plays a major role in normal brain developmental wiring [19]. Very interestingly, the lack of Cx3crl caused a transient reduction of microglia during a critical postnatal period with a consequent deficit in synaptic pruning, associated with brain functional and connectivity alterations, deficits in social interaction, and increased repetitive-behavior (phenotypes that are considered typical of autism and other neurodevelopmental and neuropsychiatric disorders) [20]. The developmental synaptic pruning, as it occurs during the peak of postnatal retinogeniculate system in the mouse, was shown to be executed by microglia engulfment of presynaptic inputs in a neural activity- and complement receptor 3/C3-dependent manner [21]. However, the interaction between neurons and microglia during the critical period of activity-dependent neural circuit refinement is bidirectional. Time-lapse imaging in the optic tectum of larval zebrafish has shown that locally elevated neuronal activity guides ramified (resting/surveying) microglial processes to contact highly active neurons (a process requiring active pannexin-1 hemichannels in neurons and small Rho GTPase Rac in microglia) and, reciprocally, microglia reduce both spontaneous and visually evoked activities of contacted neurons [22].

\section{Microglia Maladaptive Responses}

Thus, microglia functioning is regulated by the neural microenvironment and, in turn, microglia play critical roles in developmental circuit reshaping and adult brain physiological and pathological surveillance. In particular, a homeostasis alteration induces a cascade of conserved adaptive microglial responses involving biochemical, physiological, and morphological changes associated with the production of mediators that restore brain homeostasis. However, severe or prolonged alterations (such as those occurring in neurodegeneration, traumatic brain injury, stress, ageing, and neuroinflammation, but also chronic systemic inflammation) can have profound effects on microglia phenotype and functional activity which is now usually referred to as "priming" and currently the subject of intense analysis [23-27]. There is a substantial amount of clinical and experimental evidence indicating that the presence of a diseased state results in the priming for exaggerated responses to subsequent challenges or, on the contrary, a second injury aggravates the course of the first one. In experimental conditions this was described also in the case of microglial priming. In vivo primed microglia were described, for example, by using a prion disease model. In such a model, the first clinical signs appeared at week 23 after induction, but microglial activation was already detectable at week 8: systemic (but also intracerebral) LPS challenge at week 19 induced a greater production of proinflammatory mediators and a corresponding increased microglial expression of IL-1 in brain of diseased mice than in control brains [28]. Primed microglia have been proposed to be characterized by a profile consisting of (1) higher basal expression of inflammatory mediators and markers, 
(2) lower activation threshold, and (3) exaggerated inflammatory response, in comparison to unprimed microglia [25]. In the same prion model, a second experiment showed that a systemic challenge of polyinosinic:polycytidylic acid (a tolllike receptor-3 agonist mimicking inflammatory responses to systemic viral infection) accelerated underlying prion disease [29]. A similar situation was detected in a rat Parkinson model, obtained by 6-hydroxydopamine (6-OHDA) injection in the striatum, in which microglial activation is associated with neurodegeneration in the substantia nigra. In such a model, intracerebral injection of lipopolysaccharide (LPS) or chronic systemic IL-1 administration caused exacerbation of neurodegeneration and increased microglial activation in the substantia nigra [30]. In a second Parkinson model, two systemic injections of paraquat were used to induce a dopaminergic cell loss in the substantia nigra [31]. A single paraquat administration could only induce microglial activation whereas dopaminergic cell loss and oxidative stress in the substantia nigra could be elicited only after the second administration. However, if the first administration was subsequently blocked by minocycline (a microglia activation inhibitor), the second paraquat administration failed to induce any effect. On the other hand, systemic administration of LPS induced microglial activation in the substantia nigra two days after injection: at this time, a single paraquat administration was sufficient to induce nigral cell loss [31].

These experiments show that microglia priming is a critical step that leads to aggravate preexisting diseases and worsen the outcome of a secondary challenge. This was seen, for example, in traumatic brain injury in aged animals. Compared to young animals, aged ones show a higher inflammatory profile of microglia [32]. In a traumatic brain injury model (controlled cortical impact) aged animals developed larger lesions and increased neurodegeneration, associated with increased microglia activation, M1/M2 balance switch, and increased oxidative stress in comparison to young animals [33]. These effects could be the results of a switch in the activity profile of microglia induced by a first alteration in homeostasis towards an injury-dependent primed state and lead subsequently to altered responsiveness to a second challenge [34]. Indeed, stress might induce a priming stimulus for microglia via increased high mobility group box-1 protein and, in turn, produce microglial overreactivity to LPS challenge via the nucleotide-binding domain, leucine-rich repeat, and pyrin domain containing protein 3 inflammasome [35].

If there is a preexisting pathological condition the outcome of a secondary challenge could be worse than under unimpaired conditions or could aggravate the preexisting condition but also provoke unexpectedly different symptoms: for example, a secondary inflammatory challenge associated with preexisting traumatic brain injury could induce a depressive-like behavior (in addition to increased inflammatory cytokine production in microglial cells) which is not detected in uninjured animals [36]. This effect should not be unexpected, as the involvement of microglia in psychiatric, psychological, and cognitive diseases is more and more recognized [37, 38].

\section{Mediators of Microglia Maladaptive Responses}

The factors that may induce a primed state and hence a possible subsequent maladaptive response in microglia are several and they could lead to developing differential priming effects. Apart from physiological processes (such as aging) or injuries (such as trauma, both possibly involving oxidative stress), neurodegenerative processes, or prion disease inducers, specific factors have been identified and some have already been mentioned in the previous section: neurotoxins (6-OHDA, 1-methyl-4-phenyl-1,2,3,6-tetrahydropyridine, MPTP or paraquat) either systemically or directly injected into CNS parenchyma $[31,39,40]$, high mobility group box-1 which mediate the inescapable shock stress-induced priming effect [35], TLR ligands [41, 42], amyloid- $\beta(\mathrm{A} \beta)$ [43], chronic ethanol exposure [44], alpha-synuclein [45], beta-adrenergic receptor activation [46], granulocyte macrophage-colony stimulating factor (GM-CSF) [47], mycobacteria-infected macrophages [48], and DNA repair deficiency [49]. As already mentioned, oxidative stress could also provide a priming mechanism, as it occurs during aging, following ischemia or neurotoxin exposure, and it is here described more in detail.

\section{Microglia and Oxidative Stress}

Although it is still not clear whether oxidative stress is the initiating event associated with neurodegeneration, several data indicate that it is common to all neurodegenerative disorders, including Alzheimer's disease, Parkinson's disease, multiple sclerosis, and amyotrophic lateral sclerosis. Oxidative stress, due to accumulation of reactive oxygen species (ROS) (that include superoxide $\left(\mathrm{O}_{2}^{-}\right)$, hydrogen peroxide $\left(\mathrm{H}_{2} \mathrm{O}_{2}\right)$, and hydroxyl radical $\left(\mathrm{OH}^{-}\right)$) and nitric oxygen (RNS) species, is the result of an imbalance between generation of free radicals and their elimination by endogenous antioxidant mechanisms.

Activated microglia (described also as reactive microgliosis) have been shown to be an important source of ROS in response to brain injury, ischemia, or inflammatory stimuli [50-52], through mechanisms leading to stimulation of NADPH oxidase and nitric oxide synthases (NOS) activity [53-56]. This function of microglia is linked to the expression of multiple pattern recognition receptors that identify a wide number of neurotoxic stimuli. Among them, distinct members of the TLR family, in particular TLR 1-9, are essential components of the microglial innate immune response [57, 58]. TLR ligands also engage scavenger receptors (SR) that recognize modified lipoproteins and polyanionic ligands. SRA, SR-B1, CD36, and receptor for AGEs, advanced glycation endproducts (RAGE), in particular, participate in microglial activation and ROS production in response to $\mathrm{A} \beta$ fibrils [5961] (Figure 1).

Microglial pattern recognition receptors also include integrin CD11b/CD18 (MAC1, macrophage antigen complex1 , also known as complement receptor 3, CR3) that mediates LPS-induced production of superoxide and whose expression 

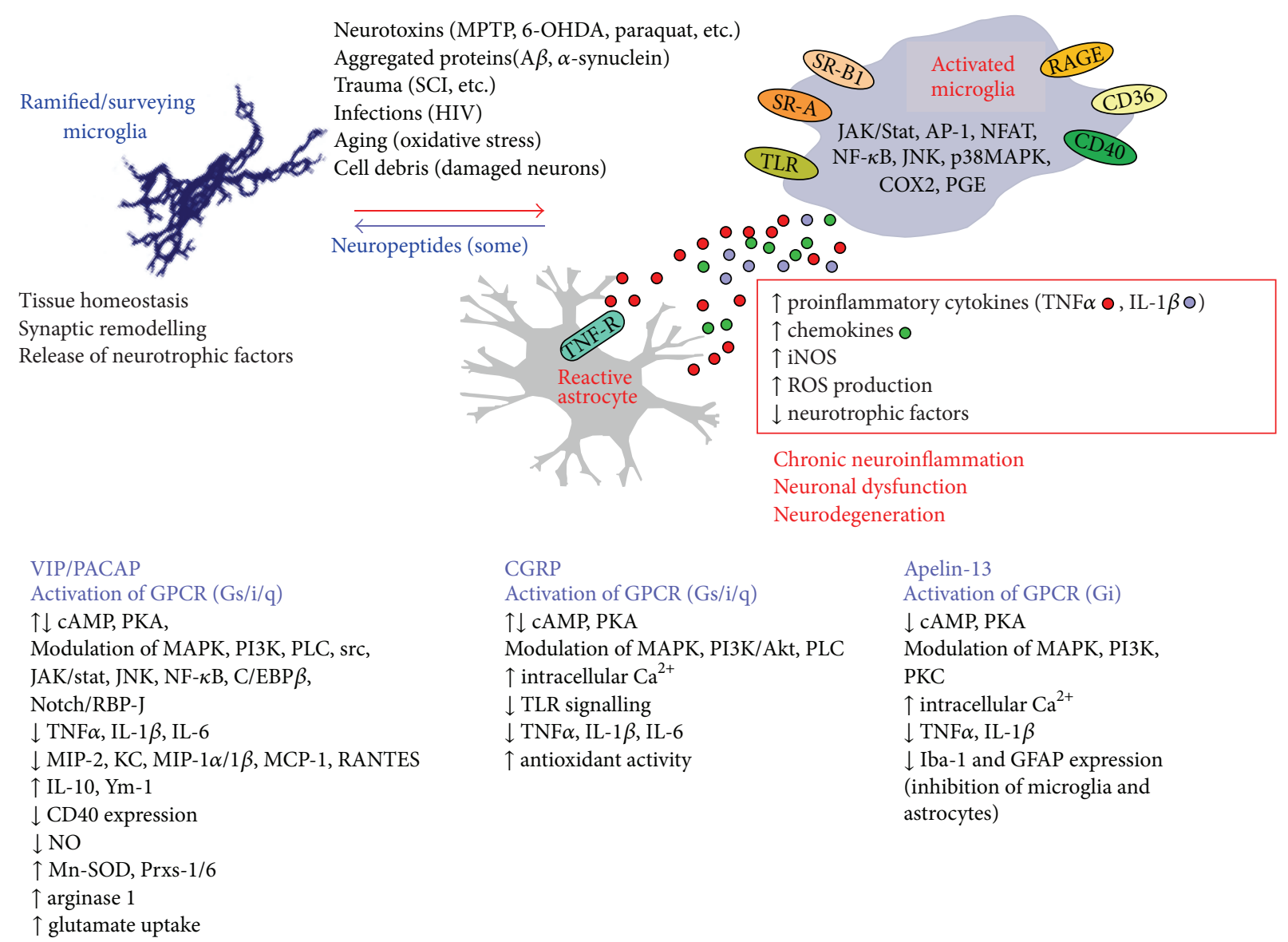

CGRP

Activation of GPCR (Gs/i/q)

$\uparrow \downarrow$ cAMP, PKA

Modulation of MAPK, PI3K/Akt, PLC

$\uparrow$ intracellular $\mathrm{Ca}^{2+}$

$\downarrow$ TLR signalling

$\downarrow$ TNF $\alpha$, IL-1 $\beta$, IL-6

$\uparrow$ antioxidant activity
Apelin-13

Activation of GPCR (Gi)

$\downarrow$ cAMP, PKA

Modulation of MAPK, PI3K,

PKC

$\uparrow$ intracellular $\mathrm{Ca}^{2+}$

$\downarrow$ TNF $\alpha$, IL- $1 \beta$

$\downarrow$ Iba-1 and GFAP expression

(inhibition of microglia and

astrocytes)

FIGURE 1: Schematic summary of microglia roles in physiological and pathological conditions in relation with the neuropeptide homeostatic influence on microglia. MPTP: 1-methyl-4-phenyl-1,2,3,6-tetrahydropyridine; 6-OHDA: 6-hydroxydopamine; A $\beta$ : beta-amyloid; SCI: spinal cord injury.

has been found to be elevated in the brains of post mortem Alzheimer's disease patients [62, 63].

Interaction of pattern recognition receptors with specific ligands stimulates NADPH oxidase and iNOS leading to production of neurotoxic factors, including toxic amounts of superoxide $\left(\mathrm{O}_{2}{ }^{-}\right)$and nitric oxide $\left(\mathrm{NO}^{\circ}\right)$ free radicals, as well as increased levels of proinflammatory cytokines (IL-1 $\beta$, TNF $\alpha$, and IL-6). Intracellular ROS and NO act as second messengers through kinase cascades (MAPKs and PI3 kinase) and transcription factors (NF- $\kappa \mathrm{B}, \mathrm{Nrf} 2$, and AP1) that modulate both microglial proinflammatory function and survival [54, 55] (Figure 1). However, dysregulation of intracellular ROS in microglia amplifies proinflammatory gene expression. Moreover, $\mathrm{NO}^{\bullet}$ and $\mathrm{O}_{2}{ }^{--}$rapidly react to form the strong oxidant peroxynitrite $\left(\mathrm{ONOO}^{-}\right)$, thus contributing to the progressive nature of microglia-mediated neurotoxicity. ROS, mainly generated at complex I (NADPH ubiquinone oxidoreductase) or ubiquinone site of complex III (ubiquinone-cytochrome $\mathrm{c}$ reductase) of the mitochondrial transport chain, further impair mitochondrial electron transport and enhance ROS production.

Increased production of ROS and proinflammatory mediators, together with the decreased secretion of neurotrophic factors, triggers neuronal homeostasis. Oxidative stress leads to mitochondrial dysfunction: decreased mitochondrial membrane potential and opening of mitochondrial permeability transition pores lead to collapse of energydependent ion transport, ATP depletion, and intracellular $\mathrm{Ca}^{+}$overload. These biochemical changes also trigger excitotoxicity caused by inhibition of glutamate uptake by the astrocytic $\mathrm{Na}^{+}$-dependent glutamate transporter-1 (GLT1, EAAT2) and glutamate-aspartate transporter (GLAST, EAAT1), most likely due to their degradation by $\mathrm{Ca}^{2+}$ activated $(\mu)$-calpains [64, 65]. Increased extracellular glutamate is also determined by nonspecific release of L-Glu by activated microglia [66] and by alteration of the glutamate/cystine antiporter, which exchanges internal glutamate for cystine [67]. EAATs seem to be expressed by microglia only under pathological situations, like following infectious diseases [68]. The relevance of neuroinflammation was also proved by the inverse association of nonsteroidal antiinflammatory drug use with the risk of Parkinson's disease in two prospective studies for nonsteroidal anti-inflammatory drug and aspirin [69]; moreover, minocycline treatment was found to reduce neuroinflammation following paraquat exposure [31].

Age-dependent alteration of gene expression and accumulation of ROS appear to be the most relevant factors for 
aging and age-related disorders. Normal aging is characterized by a mild chronic inflammatory activity and imbalance between proinflammatory (TNF $\alpha$, IL- $1 \beta$, and systemic IL-6) and anti-inflammatory cytokines (IL-10) in both the blood and the brain $[70,71]$. These aging-associated changes are believed to be responsible for increased neuronal vulnerability to synaptic damage and degeneration [72].

Neurons are particularly susceptible to oxidative damage due to their dependence on oxidative phosphorylation for their large energy demand. Moreover, the brain is rich in fatty acids, including polyunsaturated fatty acids, which are more prone to peroxidation and may trigger a chain reaction of lipid peroxidation in biomembranes. Under physiological conditions, intracellular ROS and NO act as second messengers and activate survival signalling. The increase of free radicals causes oxidative damage to proteins, lipids, and DNA and leads to decreased mitochondrial membrane potential and ATP depletion. Accumulation of lipid hydroperoxides alters membrane permeability and fluidity and oxidizes membrane proteins, leading to alterations in ion transport and intracellular flux of $\mathrm{Ca}^{2+}$. Mitochondrial dysfunction can also determine the release of cytochrome $\mathrm{c}$ and activation of intrinsic mitochondrial apoptosis.

In microglia, as in all other cell types, redox homeostasis is maintained by cellular and extracellular redox buffering systems, including the redox couples GSH/GSSG (glutathione-glutathione disulfide), cysteine/cystine, oxidized/reduced thioredoxin, and key antioxidant enzymes, including superoxide dismutase, catalase, the selenoproteins glutathione peroxidase, and thioredoxin reductase [73], as well as nonenzymatic antioxidants such as $\alpha$ tocopherol (vitamin $\mathrm{E}$ ), ascorbate (vitamin $\mathrm{C}$ ), $\beta$-carotene, and flavonoids. It is worth noting that a number of natural antioxidants and anti-inflammatory compounds have been shown to provide effective neuroprotection against oxidative stress, in both in vitro and several models of age-related neurodegenerative conditions linked to oxidative stress, such as those involved in Alzheimer's disease (A $\beta$ and tau toxicity), Parkinson's disease ( $\alpha$-synuclein, 6-OHDA, and MPTP), multiple sclerosis (experimental autoimmune encephalopathy, EAE, model), and ischemia (oxygen-glucose-deprivation) [74-77]. Antioxidant dietary supplements include polyphenols (flavonoids and resveratrol), carotenoids (lycopene), thiolic compounds (such as $\alpha$ lipoic acid, glutathione, and $\mathrm{N}$-acetylcysteine), and oligoelements (such as selenium) which are thought to exert their action on the basis of their immunomodulatory and antiinflammatory properties, as well as the capability to activate sirtuins, transcription factors (in particular, NF- $\kappa \mathrm{B}, \mathrm{Nrf} 2$, and PPAR/PGC- $1 \alpha$ ), and pathways that regulate metabolism, antioxidant responses, and cellular homeostasis [78].

\section{Microglia Maladaptive Response Regulators}

At present, there is an active search for microglia maladaptive response blockers. Among other factors, neuropeptides are emerging as new players that influence microglia activation and thus can play such a role [79]. A large array of studies shows the specific modulatory activity of many neuropeptides on microglial cells in vitro; but, in order to better relate their activity with microglia maladaptive responses in vivo, the present review focuses on the in vivo interaction between neuropeptides and microglia. In particular, the present review analyzes in vivo examples that describe the association of beneficial effects of neuropeptides on brain disease model symptoms with the regulation of inflammatory microglia activation (Table 1 ).

We will focus on presumably direct effects of neuropeptides on microglia by "brain delivery" (direct acute or chronic administrations or production through viral vectors). Caution is required in attributing the amelioration to a "direct brain effect" even in the case of "brain delivery," due to possible indirect effects through neuropeptide leakage into the bloodstream or activation of the tiny minority of nonresident immune cell that travel in and out CNS (see, e.g., [80]). However, chronic intrathecal delivery of CGRP by osmotic minipumps (in the lumbar CSF) did not produce significant changes in peripheral lymphocytes in a multiple sclerosis model, the (chronic) EAE [81].

A summary of (some) neuropeptide action and their relevance for microglia-induced maladaptive plasticity is depicted in Figure 1.

\section{VIP/PACAP Family}

Vasoactive intestinal peptide (VIP) and pituitary adenylate cyclase activating polypeptide (PACAP) are neuropeptides that belong to a family that includes peptide histidineisoleucine (PHI), peptide histidine-methionine (PHM), secretin, glucagon, glucagon-like peptide (GLP), glucosedependent insulinotropic polypeptide (GIP), growth hormone releasing hormone (GHRH), and helodermin [82]. VIP and PACAP signalling is cell type- and contextdependent and is mediated by the activation of the specific G protein-coupled receptors, VPAC1/VIPR1, VPAC2/VIPR2, and ADCYAP1R1/PAC1, which are coupled primarily to Gs that activates adenylate cyclase and in turn protein kinase A (PKA) [83], as well as exchange proteins activated by cAMP [84]. In parallel, additional pathways can be activated or inhibited in specific cells, including MAPK [85-87], phospholipase C [88], phosphatidylinositol 3-kinase [89], NO [90], src [91], Jak/STAT, and NF- $\kappa$ B $[92,93]$.

VIP and PACAP immunological actions have been extensively analyzed in vitro and in vivo and are found to be frequently superimposable. VIP can affect innate and adaptive immunity and is thought to exert primarily antiinflammatory roles $[94,95]$. Many effects of VIP, such as those directed towards influencing $\mathrm{T}$ cell differentiation and function, seem to be exerted both directly and indirectly through the immunomodulation of dendritic cells. In such a context, VIP-differentiated dendritic cells were shown to be able to restore immune tolerance in vivo, to facilitate transplantation by reducing the deleterious consequences of acute graft-versus-host disease [96]. Long lasting VIP secretion by lentiviral-VIP transduced dendritic cells had a therapeutic effect on EAE and cecal ligation and puncture sepsis models [97]. 


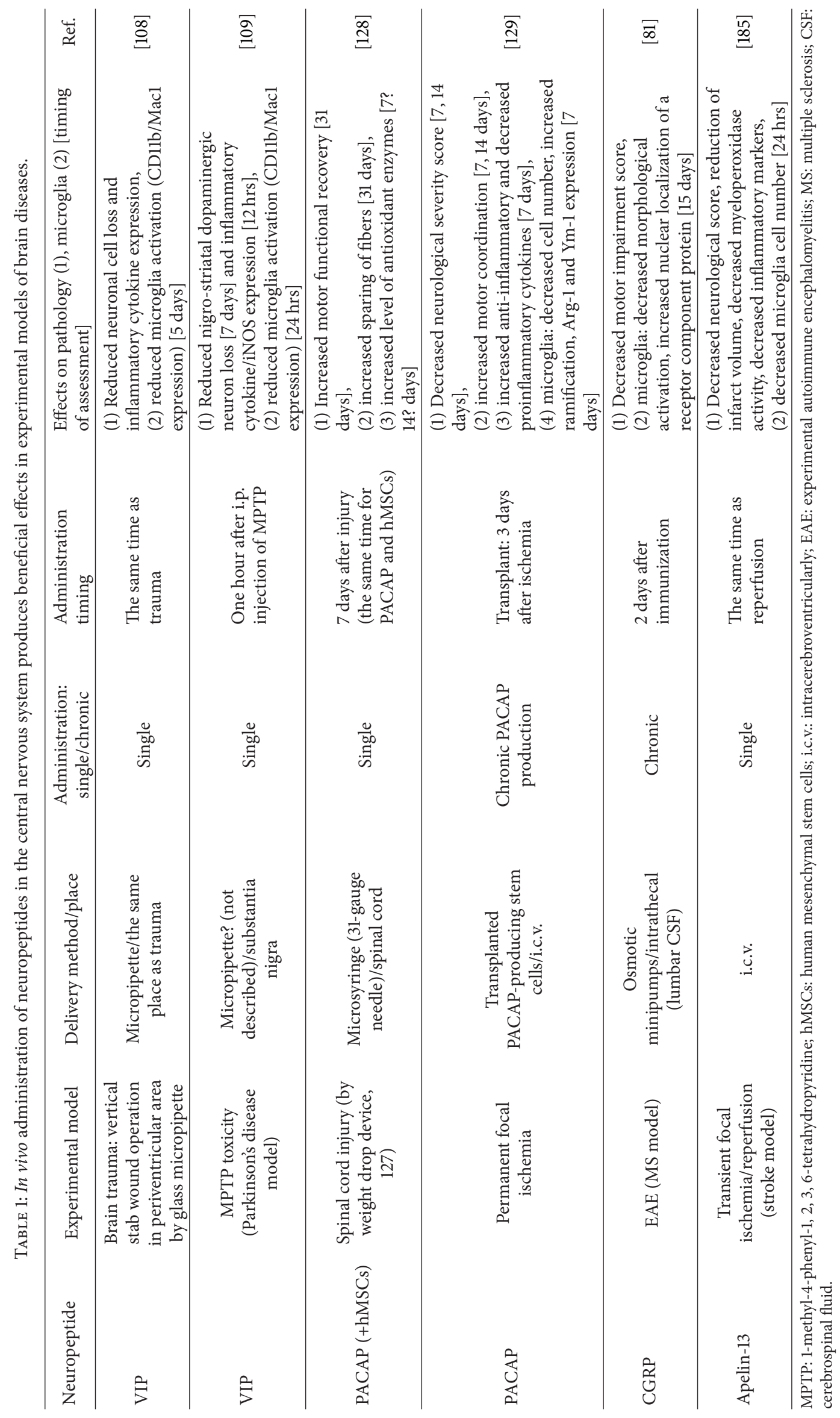


In addition to dendritic cells, macrophages are also VIP targets. For example, the peptide can inhibit phagocytosis and chemotaxis of alveolar macrophages in vitro [98] and, together with PACAP, enhance macrophage resistance to HIV-1 infection by decreasing viral growth [99]. Also the brain counterpart of macrophages, microglia, can be modulated by VIP/PACAP in vitro. In particular, PACAP activates a potassium-outward current [100] and inhibits CD40 expression [101], whereas both (with different potency) are able to inhibit inflammatory cytokines (TNF $\alpha$, IL-1 $\beta$, and IL-6), chemokines (MIP-2, KC, MIP- $1 \alpha$, MIP- $1 \beta$, MCP1 , and RANTES), and NO in LPS-activated microglia [102104], inhibit concurrently MAKK1/MEK4/JNK, CBP-NF- $\kappa$ B interaction, and stimulate JunB production $[105,106]$.

7.1. VIP. As far as CNS is concerned, in vivo experimental models of brain injuries or diseases were analyzed for VIP involvement [95]. An interesting discovery has been that VIP is upregulated in microglia following cerebrum cold injury and the VIP/VPAC2 system can induce reactive astrocytosis and neuroprotection against the injury-induced excitotoxicity [107]. Delgado and Ganea $[108,109]$ injected VIP in the brain to examine the effects of the peptide in two models, cerebral trauma and MPTP-induced dopaminergic cell loss (Parkinson's disease model). In both experimental paradigms a robust inflammatory microglia activation accompanies the pathogenesis, although its possible causative role is still a matter of investigation. In the brain trauma model (a stab wound operation), an intracerebroventricular injection of VIP, made at the same time of trauma induction, reduced neurodegeneration, recruitment of mononuclear phagocytes, inflammatory microglia activation, and local production of TNF $\alpha$ and IL-1 $\beta$ [108]. In Parkinson's disease model, an acute dosing of MPTP $(20 \mathrm{mg} / \mathrm{kg}$ intraperitoneally injected every $2 \mathrm{~h}$ for four doses) was used to induce dopaminergic cell loss in the substantia nigra [109]. A single VIP injection into the substantia nigra was effective in reducing the loss of dopaminergic neurons in the substantia nigra itself and of dopaminergic fibers in the striatum. Interestingly, the neuroprotective effect was associated with reduced inflammatory microglia activation in the substantia nigra and striatum and with a local reduction of TNF $\alpha$ expression in both structures [109]. It should be noted that the neuroprotective action was effective only if VIP injection was made within a short time after the first MPTP injection (0.5-3 hours). A third example comes from a study on a model of Alzheimer's disease, APPswe/PSEN1de9 transgenic mice. In this model, intracerebroventricular injection of recombinant adenovirus vector encoding functional VIP led to accumulation and activation of CD11b-positive microglia and a PKC-dependent increase in microglial phagocytosis of fibrillar $\mathrm{A} \beta 42$, hence attenuating amyloid deposition [110].

In the context of primed inflammatory microglia, it might be worth mentioning that VIP can decrease the inflammation-induced increase in TLR expression [111] by a homeostatic mechanism [112, 113]. In the infected cornea VIP was able to downregulate proinflammatory TLRs and upregulate anti-inflammatory TLRs [114]. Moreover, VIP can reverse TLR4 signalling in rheumatoid arthritis synovial fibroblasts [115]. Finally, VIP can suppress oxidative stress in several cell types, both in vitro $[116-118]$ and in vivo $[119,120]$.

7.2. PACAP. In addition to the described effects on microglia in vitro (see above), PACAP can protect from oxidative stress in nonneural [121, 122] but also glial cells [123]. But PACAP exerts a similar role in vivo also, as it was seen in knockout and wild-type animals [124], renal ischemia/reperfusion injury [125], and global cerebral ischemia [126].

The action of PACAP as regulator/reparative mediator acting on microglia cells in vivo was tested in a model of spinal cord injury. By using a weight-drop device [127] local injections of PACAP in synergy with human mesenchymal stem cells increased neurofilament (NF200) immunoreactivity and the levels of antioxidant enzymes, such as Mn-superoxide dismutase and peroxiredoxin-1/6, in the injured spinal cord, and led to better locomotor functional recovery [128]. In vitro, PACAP applied to microglia cocultures with hMSCs increased a subpopulation of microglia expressing galectin-3 and the uptake of extracellular glutamate by astrocytes, suggesting that the in vivo action could be mediated possibly by microglia. In a mouse stroke model, PACAP-producing stem cells were transplanted intracerebroventricularly three days after permanent focal ischemia. These cells promoted a functional recovery associated with the modulation of key transcriptional factors, such as NF- $\kappa \mathrm{B}, \mathrm{C} / \mathrm{EBP}-\beta$, and Notch/RBP$\mathrm{J}$, decreased expression of $\mathrm{TNF} \alpha$, increased expression of IL-10 and Ym-1, and increased number of arginase-1+ cells, suggesting a redirection of the microglial phenotype towards a neuroprotective M2 type [129].

The role of VIP and PACAP in this subject, however, should be analyzed taking into account the differential expression and specific involvement of their receptors. For example, in the hippocampus PACl, mRNA expression is increased at 7 days following ischemia, VPAC1 mRNA is decreased at 3 days, and VPAC2 mRNA substantially unchanged [130] whereas in a model of reactive gliosis PAC1 and VPAC2 (but not VPAC1) mRNA are increased in astrocytes (and VIP in microglia) [107]. As to the role of specific VIP/PACAP receptors in microglia, it is worth mentioning that microglial VPACl mediates proliferative and trophic effects on neural stem/progenitor cells, a role which might have relevant implications in neuroinflammatory and neurodegenerative diseases [131].

\section{CGRP}

Calcitonin Gene-Related Peptide (CGRP) is a neuropeptide that belongs to a family that includes adrenomedullin, amylin/islet amyloid polypeptide (IAPP), and calcitonin, it is mainly expressed in the CNS, by neuronal cells, and can modulate both neural and immune systems [132]. The peptide signals through a G-protein-coupled receptor named calcitoninlike receptor that makes up the common core of receptors of the family (in particular CGRP and adrenomedullin) [133]. To dictate receptor specificity (and binding capabilities), calcitonin-like receptor requires accessory proteins for its function, the single-transmembrane accessory proteins named receptor activity modifying proteins (RAMP) 1-3. In 
particular, CGRP receptor is composed of the association of calcitonin-like receptor with RAMP1 [134]. This and the other receptor complexes of the family interact with an additional cytoplasmic protein, the CGRP receptor component protein (RCP). RCP is the functional link with the intracellular signalling pathways and, in particular, with cAMP formation $[135,136]$. Activation of the CGRP receptor results in G $\alpha$ smediated increase in cAMP and subsequent activation of protein kinase A [137]. CGRP receptor, however, can couple to additional $G$ proteins (as well as to other proteins, such as arrestins) to confer signalling. This includes $\mathrm{G} \alpha \mathrm{q} / 11$-mediated phospholipase $C-\beta 1$ activation, intracellular calcium increase, mitogen-activated protein kinase (MAPK) cascade activation, and NO production [138-141]. Cellular background and context-dependence play a critical role as determinants for the activation of specific signalling pathways, as shown, for example, for calcium and MAPK $[139,141,142]$.

As suggested for other neuropeptides, CGRP is thought to maintain homeostasis [143-145], a role which seems to be evolutionarily conserved as it has been assigned also to calcitonin (a peptide of the family) in zebrafish [146]. Coherently with a homeostatic role, CGRP can promote neurogenic inflammation in the periphery [147] and brain during headache [148] but also protect against local (LPSinduced) inflammatory or immune-mediated injuries [149, 150]. The peptide can directly induce the secretion of a variety of cytokines from $\mathrm{T}$ cells [151] and regulate the functions of several immune cells, including macrophages, $\mathrm{T}$ and $\mathrm{B}$ lymphocytes, and Langerhans cells [152-156].

In the brain, its receptors are expressed in all neural cells [81]. In vitro, CGRP potently inhibits the secretion of proinflammatory mediators from LPS-activated microglia in a dose-dependent manner [157]. This effect is carried out also by adrenomedullin, a closely related peptide of the family, and spreads to involve astrocytes, when cocultured with microglia [157]. In vivo, CGRP has been applied intrathecally (in the lumbar cerebrospinal fluid) during the induction phase of the experimental autoimmune encephalopathy, an animal model of multiple sclerosis. In this model and in multiple sclerosis, inflammatory microglia activation is thought to be involved from the early stages of the pathogenesis [158161]. CGRP delivery into the cerebrospinal fluid reduced chronic experimental autoimmune encephalopathy signs while inhibiting microglia activation [81]. The analysis of RCP (probe for CGRP receptor involvement) showed that, in a relapsing-remitting form of experimental autoimmune encephalopathy, its expression increased during the relapsing phase in parallel with an increase in its nuclear localization in microglia. The nuclear localization of RCP could be induced also by CGRP itself both in cultured cells in vitro and in microglia in vivo following the peptide delivery in the cerebrospinal fluid during experimental autoimmune encephalopathy [81].

CGRP can regulate several pathways. For example, it was shown to interfere with TLR signalling, as seen in murine dendritic cells in which the peptide potently inhibited TLR-stimulated production of inflammatory mediators [162]. In addition the peptide exerts an antioxidant activity, as described in vitro [163-166], in an isolated heart preparation [167], and in vivo [168, 169].

\section{Apelin-13}

Apelin was identified as the endogenous ligand of the $G$ protein-coupled receptor APJ, and its name derives from this discovery (i.e., APJ endogenous ligand) [170]. Following the purification from stomach extracts, a 36-amino acid peptide was isolated and sequenced (apelin-36). The corresponding cDNA identified a preproprotein of 77 amino acids containing the 36-amino acid peptide, apelin (42-77). Sequence alignment from different species revealed a strong conservation of the entire amino acid sequence, with a highest identity in the C-terminal region [171]. However, the potential existence of additional ligands was also hypothesized on the basis of the presence of two conserved basic doublets, apelin17 and apelin-13 [172].

The receptor was thought to be involved in HIV infection, and so its ligand. However, the range of its functions widened soon [173]. At present, apelin is considered to be a pleiotropic peptide with a homeostatic function (as other neuropeptides). Its receptor, APJ, is expressed in the CNS at high levels, its mRNA expression being intense in the hypothalamic paraventricular and supraoptic nuclei and in the anterior and intermediate lobe of the pituitary, the pineal gland and nuclei of the olfactory system $[174,175]$. Outside the brain, expression of the amphibian apelin receptor was first associated with an endothelial lineage [176] and it was later shown to be expressed in human heart and saphenous vein [177]; it can be upregulated in peripheral blood mononuclear cells [178]. Its actions include roles in the cardiovascular system [179], ischemia/reperfusion injury [180], pulmonary arterial hypertension [181], feeding behavior, gastrointestinal function, and fluid homeostasis [182].

The intracellular cascades activated by apelins include inhibition of production of cAMP (in CHO cells stably transfected with the apelin receptor [174]) and rise in intracellular calcium concentrations [183], and activate ERKs via a PTX-sensitive G protein and a PKC isoform in $\mathrm{CHO}$ cells expressing the murine apelin receptor [184].

Apelin-13 was found to exert a neuroprotective action in a stroke model. Following a transient focal ischemia/reperfusion injury model, the intracerebroventricular administration of the peptide at the onset of reperfusion reduced the infarct volume and the neurological deficits and inhibited the increase of myeloperoxidase activity. Moreover, the peptide was shown to decrease the expression of inflammatory cytokines as well as that one of Ibal and GFAP indicating inhibition of microglia and astrocytes [185]. It is unclear whether apelin-13 can target directly microglia in this stroke model, and it is worth noting that its receptor was not detected neither in cultured microglial cells [183] nor in spinal cord microglial cells of SOD1(G93A) mice, a model of amyotrophic lateral sclerosis. Interestingly, however, apelin-13 and two structural analogues showed inhibition of mitochondrial ROS in cardiac cells, and, in a model of ischemia/reperfusion injury, preischemic infusion 
significantly reduced ROS formation and attenuated cell membrane damage [186].

\section{Conclusion}

There is a general agreement that microglia are a main homeostatic player in the brain, during development, by influencing synaptic activity and circuitry, and in pathological conditions. Although potentially beneficial, microglia activation can lead to a priming effect that can produce deleterious (instead of protective), self-sustaining effects. There is a growing body of evidence that a derangement from its physiological function transforms microglia in a major detrimental player in a variety of brain pathological conditions, ranging from trauma, infection, neuroinflammation, and neurodegeneration. This maladaptive microglial response needs to be targeted to dampen damage, invert vicious cycles, and restore cellular functions.

Among the modulators of microglia activation, neuropeptides have been recently used in vivo in different brain disease models. In addition to a potent in vitro effect, VIP, PACAP, CGRP, and apelin-13 have been shown to be able to dampen microglia activation also in vivo and to produce strong beneficial effects or at least reduce the symptom severity. Most of the administration procedures have used a delivery timing which cannot allow a clear-cut indication for a therapeutical effect of these molecules at present, but the very recent results of PACAP application in stroke are, instead, in this line [129]. Even though the pleiotropic (and homeostatic) effects of the neuropeptides imply that their action have to be analyzed carefully in each specific pathological condition (see, e.g., the neuroprotective effect of a substance P antagonist in a Parkinson's model [187]), it can be suggested that the neuropeptides are well suited to act as inhibitors of microglia activation in different brain disease models in vivo. Their microglial modulatory effects are accompanied by significant symptom amelioration and it can thus be anticipated that they may well become part of the therapeutical repertoire for brain diseases in the future.

\section{Conflict of Interests}

The authors declare that there is no conflict of interests regarding the publication of this paper.

\section{Acknowledgments}

Work in the laboratory of the authors was supported by grants from FISM (Fondazione Italiana Sclerosi Multipla, http://www.aism.it) cod. 2011/R/27 (Stefano Morara); Regione Lombardia, Biotechnology Programme, NUTEC Project, ID 30263049 (Stefano Morara); Italian Minister of University and Research (MIUR), PRIN2007 (Anna Maria Colangelo); SYSBIONET Italian ROADMAP ESFRI Infrastructures (Anna Maria Colangelo); and IVASCOMAR Cluster Nazionale (Anna Maria Colangelo).

\section{References}

[1] C. N. Serhan, N. Chiang, J. Dalli, and B. D. Levy, "Lipid mediators in the resolution of inflammation," Cold Spring Harbor Perspectives in Biology, vol. 7, no. 2, 2015.

[2] A. Ortega-Gómez, M. Perretti, and O. Soehnlein, "Resolution of inflammation: an integrated view," EMBO Molecular Medicine, vol. 5, no. 5, pp. 661-674, 2013.

[3] S. S. Pullamsetti, R. Savai, W. Janssen et al., "Inflammation, immunological reaction and role of infection in pulmonary hypertension," Clinical Microbiology and Infection, vol. 17, no. 1, pp. 7-14, 2011.

[4] J. V. Bonventre and L. Yang, "Cellular pathophysiology of ischemic acute kidney injury," Journal of Clinical Investigation, vol. 121, no. 11, pp. 4210-4221, 2011.

[5] C. Weber and H. Noels, "Atherosclerosis: current pathogenesis and therapeutic options," Nature Medicine, vol. 17, no. 11, pp. 1410-1422, 2011.

[6] P. A. B. Wark, V. Murphy, and J. Mattes, "The interaction between mother and fetus and the development of allergic asthma," Expert Review of Respiratory Medicine, vol. 8, no. 1, pp. 57-66, 2014.

[7] X. Zhang and J. Köhl, "A complex role for complement in allergic asthma," Expert Review of Clinical Immunology, vol. 6, no. 2, pp. 269-277, 2010.

[8] I. Schmudde, Y. Laumonnier, and J. Köhl, "Anaphylatoxins coordinate innate and adaptive immune responses in allergic asthma," Seminars in Immunology, vol. 25, no. 1, pp. 2-11, 2013.

[9] V. O. Millien, W. Lu, G. Mak et al., "Airway fibrinogenolysis and the initiation of allergic inflammation," Annals of the American Thoracic Society, vol. 11, supplement 5, pp. S277-S283, 2014.

[10] J. L. Barlow and A. N. J. McKenzie, "Type-2 innate lymphoid cells in human allergic disease," Current Opinion in Allergy and Clinical Immunology, vol. 14, no. 5, pp. 397-403, 2014.

[11] P. Shivshankar, G. V. Halade, C. Calhoun et al., "Caveolin-1 deletion exacerbates cardiac interstitial fibrosis by promoting M2 macrophage activation in mice after myocardial infarction," Journal of Molecular and Cellular Cardiology, vol. 76, pp. 84-93, 2014.

[12] K. J. Moore, F. J. Sheedy, and E. A. Fisher, "Macrophages in atherosclerosis: a dynamic balance," Nature Reviews Immunology, vol. 13, no. 10, pp. 709-721, 2013.

[13] I. Galea, I. Bechmann, and V. H. Perry, "What is immune privilege (not)?" Trends in Immunology, vol. 28, no. 1, pp. 12$18,2007$.

[14] R. M. Ransohoff and B. Engelhardt, "The anatomical and cellular basis of immune surveillance in the central nervous system," Nature Reviews Immunology, vol. 12, no. 9, pp. 623-635, 2012.

[15] K. Helmut, U.-K. Hanisch, M. Noda, and A. Verkhratsky, "Physiology of microglia," Physiological Reviews, vol. 91, no. 2, pp. 461-553, 2011.

[16] A. Nimmerjahn, F. Kirchhoff, and F. Helmchen, "Neuroscience: resting microglial cells are highly dynamic surveillants of brain parenchyma in vivo," Science, vol. 308, no. 5726, pp. 1314-1318, 2005.

[17] D. Davalos, J. Grutzendler, G. Yang et al., "ATP mediates rapid microglial response to local brain injury in vivo," Nature Neuroscience, vol. 8, no. 6, pp. 752-758, 2005.

[18] H. Wake, A. J. Moorhouse, S. Jinno, S. Kohsaka, and J. Nabekura, "Resting microglia directly monitor the functional state of 
synapses in vivo and determine the fate of ischemic terminals," The Journal of Neuroscience, vol. 29, no. 13, pp. 3974-3980, 2009.

[19] R. C. Paolicelli, G. Bolasco, F. Pagani et al., "Synaptic pruning by microglia is necessary for normal brain development," Science, vol. 333, no. 6048, pp. 1456-1458, 2011.

[20] Y. Zhan, R. C. Paolicelli, F. Sforazzini et al., "Deficient neuronmicroglia signaling results in impaired functional brain connectivity and social behavior," Nature Neuroscience, vol. 17, no. 3, pp. 400-406, 2014.

[21] D. P. Schafer, E. K. Lehrman, A. G. Kautzman et al., "Microglia sculpt postnatal neural circuits in an activity and complementdependent manner," Neuron, vol. 74, no. 4, pp. 691-705, 2012.

[22] Y. Li, X.-F. Du, C.-S. Liu, Z.-L. Wen, and J.-L. Du, "Reciprocal regulation between resting microglial dynamics and neuronal activity in vivo," Developmental Cell, vol. 23, no. 6, pp. 1189-1202, 2012.

[23] C. Cunningham, "Microglia and neurodegeneration: the role of systemic inflammation,” Glia, vol. 61, no. 1, pp. 71-90, 2013.

[24] V. H. Perry and J. Teeling, "Microglia and macrophages of the central nervous system: the contribution of microglia priming and systemic inflammation to chronic neurodegeneration," Seminars in Immunopathology, vol. 35, no. 5, pp. 601-612, 2013.

[25] D. M. Norden, M. M. Muccigrosso, and J. P. Godbout, "Microglial priming and enhanced reactivity to secondary insult in aging, and traumatic CNS injury, and neurodegenerative disease," Neuropharmacology, vol. 96, part A, pp. 29-41, 2015.

[26] V. H. Perry and C. Holmes, "Microglial priming in neurodegenerative disease," Nature Reviews Neurology, vol. 10, no. 4, pp. 217-224, 2014.

[27] J. C. Delpech, C. Madore, A. Nadjar, C. Joffre, E. S. Wohleb, and S. Layé, "Microglia in neuronal plasticity: influence of stress," Neuropharmacology, vol. 96, pp. 19-28, 2015.

[28] C. Cunningham, D. C. Wilcockson, S. Campion, K. Lunnon, and V. H. Perry, "Central and systemic endotoxin challenges exacerbate the local inflammatory response and increase neuronal death during chronic neurodegeneration," The Journal of Neuroscience, vol. 25, no. 40, pp. 9275-9284, 2005.

[29] R. Field, S. Campion, C. Warren, C. Murray, and C. Cunningham, "Systemic challenge with the TLR3 agonist poly I: C induces amplified IFN $\alpha / \beta$ and IL- $1 \beta$ responses in the diseased brain and exacerbates chronic neurodegeneration," Brain, Behavior, and Immunity, vol. 24, no. 6, pp. 996-1007, 2010.

[30] M. C. P. Godoy, R. Tarelli, C. C. Ferrari, M. I. Sarchi, and F. J. Pitossi, "Central and systemic IL-1 exacerbates neurodegeneration and motor symptoms in a model of Parkinson's disease," Brain, vol. 131, no. 7, pp. 1880-1894, 2008.

[31] M. G. Purisai, A. L. McCormack, S. Cumine, J. Li, M. Z. Isla, and D. A. Di Monte, "Microglial activation as a priming event leading to paraquat-induced dopaminergic cell degeneration," Neurobiology of Disease, vol. 25, no. 2, pp. 392-400, 2007.

[32] D. M. Norden and J. P. Godbout, "Review: microglia of the aged brain: primed to be activated and resistant to regulation," Neuropathology and Applied Neurobiology, vol. 39, no. 1, pp. 1934, 2013.

[33] A. Kumar, B. A. Stoica, B. Sabirzhanov, M. P. Burns, A. I. Faden, and D. J. Loane, "Traumatic brain injury in aged animals increases lesion size and chronically alters microglial/macrophage classical and alternative activation states," Neurobiology of Aging, vol. 34, no. 5, pp. 1397-1411, 2013.
[34] K. Palin, C. Cunningham, P. Forse, V. H. Perry, and N. Platt, "Systemic inflammation switches the inflammatory cytokine profile in CNS Wallerian degeneration," Neurobiology of Disease, vol. 30, no. 1, pp. 19-29, 2008.

[35] M. D. Weber, M. G. Frank, K. J. Tracey, L. R. Watkins, and S. F. Maier, "Stress induces the danger-associated molecular pattern HMGB-1 in the hippocampus of male sprague dawley rats: a priming stimulus of microglia and the NLRP3 inflammasome," Journal of Neuroscience, vol. 35, no. 1, pp. 316-324, 2015.

[36] A. M. Fenn, J. C. Gensel, Y. Huang, P. G. Popovich, J. Lifshitz, and J. P. Godbout, "Immune activation promotes depression 1 month after diffuse brain injury: a role for primed microglia," Biological Psychiatry, vol. 76, no. 7, pp. 575-584, 2014.

[37] L. R. Frick, K. Williams, and C. Pittenger, "Microglial dysregulation in psychiatric disease," Clinical and Developmental Immunology, vol. 2013, Article ID 608654, 10 pages, 2013.

[38] M. Prinz and J. Priller, "Microglia and brain macrophages in the molecular age: from origin to neuropsychiatric disease," Nature Reviews Neuroscience, vol. 15, no. 5, pp. 300-312, 2014.

[39] H. Akiyama and P. L. McGeer, "Microglial response to 6hydroxydopamine-induced substantia nigra lesions," Brain Research, vol. 489, no. 2, pp. 247-253, 1989.

[40] J. W. Francis, J. Von Visger, G. J. Markelonis, and T. H. Oh, "Neuroglial responses to the dopaminergic neurotoxicant 1-methyl-4-phenyl-1,2,3,6-tetrahydropyridine in mouse striatum," Neurotoxicology and Teratology, vol. 17, no. 1, pp. 7-12, 1995.

[41] L. Facci, M. Barbierato, C. Marinelli, C. Argentini, S. D. Skaper, and P. Giusti, "Toll-like receptors 2, -3 and -4 prime microglia but not astrocytes across central nervous system regions for ATP-dependent interleukin-1 $\beta$ release," Scientific Reports, vol. 4, article 6824, 2014.

[42] M. D. Weber, M. G. Frank, J. L. Sobesky, L. R. Watkins, and S. F. Maier, "Blocking toll-like receptor 2 and 4 signaling during a stressor prevents stress-induced priming of neuroinflammatory responses to a subsequent immune challenge," Brain, Behavior, and Immunity, vol. 32, pp. 112-121, 2013.

[43] T. Schilling and C. Eder, "Amyloid- $\beta$-induced reactive oxygen species production and priming are differentially regulated by ion channels in microglia," Journal of Cellular Physiology, vol. 226, no. 12, pp. 3295-3302, 2011.

[44] L. Qin and F. T. Crews, "Chronic ethanol increases systemic TLR3 agonist-induced neuroinflammation and neurodegeneration," Journal of Neuroinflammation, vol. 9, article 130, 2012.

[45] C. Roodveldt, A. Labrador-Garrido, E. Gonzalez-Rey et al., "Preconditioning of microglia by $\alpha$-synuclein strongly affects the response induced by toll-like receptor (TLR) stimulation," PLoS ONE, vol. 8, no. 11, Article ID e79160, 2013.

[46] J. D. Johnson, Z. R. Zimomra, and L. T. Stewart, "Betaadrenergic receptor activation primes microglia cytokine production," Journal of Neuroimmunology, vol. 254, no. 1-2, pp. 161164, 2013.

[47] B. Parajuli, Y. Sonobe, J. Kawanokuchi et al., “GM-CSF increases LPS-induced production of proinflammatory mediators via upregulation of TLR4 and CD14 in murine microglia," Journal of Neuroinflammation, vol. 9, article 268, 2012.

[48] H.-M. Lee, J. Kang, S. J. Lee, and E.-K. Jo, "Microglial activation of the NLRP3 inflammasome by the priming signals derived from macrophages infected with mycobacteria," Glia, vol. 61, no. 3, pp. 441-452, 2013. 
[49] D. D. A. Raj, D. Jaarsma, I. R. Holtman et al., "Priming of microglia in a DNA-repair deficient model of accelerated aging," Neurobiology of Aging, vol. 35, no. 9, pp. 2147-2160, 2014.

[50] S. Pawate, Q. Shen, F. Fan, and N. R. Bhat, "Redox regulation of glial inflammatory response to lipopolysaccharide and interferon gamma," Journal of Neuroscience Research, vol. 77, no. 4, pp. 540-551, 2004.

[51] D. Kim, B. You, E.-K. Jo, S.-K. Han, M. I. Simon, and S. J. Lee, "NADPH oxidase 2-derived reactive oxygen species in spinal cord microglia contribute to peripheral nerve injuryinduced neuropathic pain," Proceedings of the National Academy of Sciences of the United States of America, vol. 107, no. 33, pp. 14851-14856, 2010.

[52] M. L. Block, L. Zecca, and J.-S. Hong, "Microglia-mediated neurotoxicity: uncovering the molecular mechanisms," Nature Reviews Neuroscience, vol. 8, no. 1, pp. 57-69, 2007.

[53] M. T. Fischer, R. Sharma, J. L. Lim et al., "NADPH oxidase expression in active multiple sclerosis lesions in relation to oxidative tissue damage and mitochondrial injury," Brain, vol. 135, no. 3, pp. 886-899, 2012.

[54] E. A. Bordt and B. M. Polster, "NADPH oxidase- and mitochondria-derived reactive oxygen species in proinflammatory microglial activation: a bipartisan affair?" Free Radical Biology and Medicine, vol. 76, pp. 34-46, 2014.

[55] R. P. Brandes, N. Weissmann, and K. Schröder, "Nox family NADPH oxidases: molecular mechanisms of activation," Free Radical Biology and Medicine, vol. 76, pp. 208-226, 2014.

[56] A. I. Rojo, G. McBean, M. Cindric et al., "Redox control of microglial function: molecular mechanisms and functional significance," Antioxidants \& Redox Signaling, vol. 21, no. 12, pp. 1766-1801, 2014.

[57] C. S. Jack, N. Arbour, J. Manusow et al., "TLR signaling tailors innate immune responses in human microglia and astrocytes," Journal of Immunology, vol. 175, no. 7, pp. 4320-4330, 2005.

[58] J. K. Olson and S. D. Miller, "Microglia initiate central nervous system innate and adaptive immune responses through multiple TLRs," Journal of Immunology, vol. 173, no. 6, pp. 3916-3924, 2004.

[59] J. Husemann, J. D. Loike, T. Kodama, and S. C. Silverstein, "Scavenger receptor class B type I (SR-BI) mediates adhesion of neonatal murine microglia to fibrillar $\beta$-amyloid," Journal of Neuroimmunology, vol. 114, no. 1-2, pp. 142-150, 2001.

[60] I. S. Coraci, J. Husemann, J. W. Berman et al., "CD36, a class B scavenger receptor, is expressed on microglia in Alzheimer's disease brains and can mediate production of reactive oxygen species in response to $\beta$-amyloid fibrils," American Journal of Pathology, vol. 160, no. 1, pp. 101-112, 2002.

[61] O. Arancio, H. P. Zhang, X. Chen et al., "RAGE potentiates A $\beta$ induced perturbation of neuronal function in transgenic mice," The EMBO Journal, vol. 23, no. 20, pp. 4096-4105, 2004.

[62] H. Akiyama and P. L. McGeer, "Brain microglia constitutively express $\beta$-2 integrins," Journal of Neuroimmunology, vol. 30, no. 1, pp. 81-93, 1990.

[63] Z. Pei, H. Pang, L. Qian et al., "MAC1 mediates LPS-induced production of superoxide by microglia: the role of pattern recognition receptors in dopaminergic neurotoxicity," Glia, vol. 55, no. 13, pp. 1362-1373, 2007.

[64] A. M. Colangelo, L. Alberghina, and M. Papa, "Astrogliosis as a therapeutic target for neurodegenerative diseases," Neuroscience Letters, vol. 565, pp. 59-64, 2014.
[65] C. Cavaliere, G. Cirillo, M. R. Rosaria Bianco et al., "Gliosis alters expression and uptake of spinal glial amino acid transporters in a mouse neuropathic pain model," Neuron Glia Biology, vol. 3, no. 2, pp. 141-153, 2007.

[66] J. Takaki, K. Fujimori, M. Miura, T. Suzuki, Y. Sekino, and K. Sato, "L-glutamate released from activated microglia downregulates astrocytic L-glutamate transporter expression in neuroinflammation: the 'collusion' hypothesis for increased extracellular L-glutamate concentration in neuroinflammation," Journal of Neuroinflammation, vol. 9, article 275, 2012.

[67] A. M. Colangelo, G. Cirillo, M. L. Lavitrano, L. Alberghina, and M. Papa, "Targeting reactive astrogliosis by novel biotechnological strategies," Biotechnology Advances, vol. 30, no. 1, pp. 261271, 2012.

[68] M. Persson and L. Rönnbäck, "Microglial self-defence mediated through GLT-1 and glutathione," Amino Acids, vol. 42, no. 1, pp. 207-219, 2012.

[69] H. Chen, E. Jacobs, M. A. Schwarzschild et al., "Nonsteroidal anti-inflammatory drug use and the risk of Parkinson's disease," Annals of Neurology, vol. 59, pp. 988-989, 2005.

[70] W. J. Lukiw, "Gene expression profiling in fetal, aged, and Alzheimer hippocampus: a continuum of stress-related signaling," Neurochemical Research, vol. 29, no. 6, pp. 1287-1297, 2004.

[71] W. J. Streit, N. W. Sammons, A. J. Kuhns, and D. L. Sparks, "Dystrophic microglia in the aging human brain," Glia, vol. 45, no. 2, pp. 208-212, 2004.

[72] M. P. Mattson and T. Magnus, "Ageing and neuronal vulnerability," Nature Reviews Neuroscience, vol. 7, no. 4, pp. 278-294, 2006.

[73] R. Banerjee, "Redox outside the box: linking extracellular redox remodeling with intracellular redox metabolism," The Journal of Biological Chemistry, vol. 287, no. 7, pp. 4397-4402, 2012.

[74] J. Bournival, P. Quessy, and M.-G. Martinoli, "Protective effects of resveratrol and quercetin against $\mathrm{MPP}+$-induced oxidative stress act by modulating markers of apoptotic death in dopaminergic neurons," Cellular and Molecular Neurobiology, vol. 29, no. 8, pp. 1169-1180, 2009.

[75] M. Morini, L. Roccatagliata, R. Dell'Eva et al., “ $\alpha$-Lipoic acid is effective in prevention and treatment of experimental autoimmune encephalomyelitis," Journal of Neuroimmunology, vol. 148, no. 1-2, pp. 146-153, 2004.

[76] A. V. Rao and L. G. Rao, "Carotenoids and human health," Pharmacological Research, vol. 55, no. 3, pp. 207-216, 2007.

[77] C. Ramassamy, "Emerging role of polyphenolic compounds in the treatment of neurodegenerative diseases: a review of their intracellular targets," European Journal of Pharmacology, vol. 545, no. 1, pp. 51-64, 2006.

[78] L. Gan and L. Mucke, "Paths of convergence: sirtuins in aging and neurodegeneration," Neuron, vol. 58, no. 1, pp. 10-14, 2008.

[79] E. Reinke and Z. Fabry, "Breaking or making immunological privilege in the central nervous system: the regulation of immunity by neuropeptides," Immunology Letters, vol. 104, no. 1-2, pp. 102-109, 2006.

[80] B. Engelhardt and R. M. Ransohoff, "The ins and outs of T-lymphocyte trafficking to the CNS: anatomical sites and molecular mechanisms," Trends in Immunology, vol. 26, no. 9, pp. 485-495, 2005.

[81] C. Sardi, L. Zambusi, A. Finardi et al., "Involvement of calcitonin gene-related peptide and receptor component protein in experimental autoimmune encephalomyelitis," Journal of Neuroimmunology, vol. 271, no. 1-2, pp. 18-29, 2014. 
[82] N. M. Sherwood, S. L. Krueckl, and J. E. McRory, “The origin and function of the pituitary adenylate cyclase-activating polypeptide (PACAP)/glucagon superfamily," Endocrine Reviews, vol. 21, no. 6, pp. 619-670, 2000.

[83] M. Delgado, D. Pozo, and D. Ganea, "The significance of vasoactive intestinal peptide in immunomodulation," Pharmacological Reviews, vol. 56, no. 2, pp. 249-290, 2004.

[84] J. Ster, F. De Bock, N. C. Guérineau et al., "Exchange protein activated by cAMP (EPAC) mediates cAMP activation of $\mathrm{p} 38$ MAPK and modulation of $\mathrm{Ca}^{2+}$-dependent $\mathrm{K}^{+}$channels in cerebellar neurons," Proceedings of the National Academy of Sciences of the United States of America, vol. 104, no. 7, pp. 25192524, 2007.

[85] A. P. Barrie, A. M. Clohessy, C. S. Buensuceso, M. V. Rogers, and J. M. Allen, "Pituitary adenylyl cyclase-activating peptide stimulates extracellular signal-regulated kinase 1 or 2 (ERK1/2) activity in a Ras-independent, mitogen-activated protein kinase/ERK kinase 1 or 2-dependent manner in PC12 cells," The Journal of Biological Chemistry, vol. 272, no. 32, pp. 19666-19671, 1997.

[86] M. Villalba, J. Bockaert, and L. Journot, "Pituitary adenylate cyclase-activating polypeptide (PACAP-38) protects cerebellar granule neurons from apoptosis by activating the mitogenactivated protein kinase (MAP kinase) pathway," The Journal of Neuroscience, vol. 17, no. 1, pp. 83-90, 1997.

[87] V. Lelièvre, N. Pineau, J. Du et al., "Differential effects of peptide histidine isoleucine (PHI) and related peptides on stimulation and suppression of neuroblastoma cell proliferation. A novel VIP-independent action of PHI via MAP kinase," The Journal of Biological Chemistry, vol. 273, no. 31, pp. 19685-19690, 1998.

[88] D. Spengler, C. Waeber, C. Pantaloni et al., "Differential signal transduction by five splice variants of the PACAP receptor," Nature, vol. 365, no. 6442, pp. 170-175, 1993.

[89] S. G. Straub and G. W. G. Sharp, "A wortmannin-sensitive signal transduction pathway is involved in the stimulation of insulin release by vasoactive intestinal polypeptide and pituitary adenylate cyclase-activating polypeptide," The Journal of Biological Chemistry, vol. 271, no. 3, pp. 1660-1668, 1996.

[90] K. S. Murthy, K. M. Zhang, J. G. Jin, J. R. Grider, and G. M. Makhlouf, "VIP-mediated G protein-coupled $\mathrm{Ca}^{2+}$ influx activates a constitutive NOS in dispersed gastric muscle cells," American Journal of Physiology, vol. 265, no. 4, part 1, pp. G660G671, 1993.

[91] S.-W. M. Koh, "Signal transduction through the vasoactive intestinal peptide receptor stimulates phosphorylation of the tyrosine kinase pp60c-src," Biochemical and Biophysical Research Communications, vol. 174, no. 2, pp. 452-458, 1991.

[92] M. Delgado and D. Ganea, "Vasoactive intestinal peptide and pituitary adenylate cyclase-activating polypeptide inhibit interleukin-12 transcription by regulating nuclear factor $\kappa \mathrm{B}$ and Ets activation," The Journal of Biological Chemistry, vol. 274, no. 45, pp. 31930-31940, 1999.

[93] M. Delgado and D. Ganea, "Inhibition of IFN- $\gamma$-induced Janus kinase-1-STAT1 activation in macrophages by vasoactive intestinal peptide and pituitary adenylate cyclase-activating polypeptide," Journal of Immunology, vol. 165, no. 6, pp. 30513057, 2000.

[94] M. Delgado and D. Ganea, "Vasoactive intestinal peptide: a neuropeptide with pleiotropic immune functions," Amino Acids, vol. 45, no. 1, pp. 25-39, 2013.
[95] J. A. Waschek, "VIP and PACAP: neuropeptide modulators of CNS inflammation, injury, and repair," British Journal of Pharmacology, vol. 169, no. 3, pp. 512-523, 2013.

[96] A. Chorny, E. Gonzalez-Rey, A. Fernandez-Martin, D. Ganea, and M. Delgado, "Vasoactive intestinal peptide induces regulatory dendritic cells that prevent acute graft-versus-host disease while maintaining the graft-versus-tumor response," Blood, vol. 107, no. 9, pp. 3787-3794, 2006.

[97] M. G. Toscano, M. Delgado, W. Kong, F. Martin, M. Skarica, and D. Ganea, "Dendritic cells transduced with lentiviral vectors expressing vip differentiate into vip-secreting tolerogenic-like DCs," Molecular Therapy, vol. 18, no. 5, pp. 1035-1045, 2010.

[98] D. K. Litwin, A. K. Wilson, and S. I. Said, "Vasoactive intestinal polypeptide (VIP) inhibits rat alveolar macrophage phagocytosis and chemotaxis in vitro," Regulatory Peptides, vol. 40, no. 1, pp. 63-74, 1992.

[99] J. R. Temerozo, R. Joaquim, E. G. Regis, W. Savino, and D. C. Bou-Habib, "Macrophage resistance to HIV-1 infection is enhanced by the neuropeptides VIP and PACAP," PLoS ONE, vol. 8, no. 6, Article ID e67701, 2013.

[100] M. Ichinose, M. Asai, and M. Sawada, "Activation of outward current by pituitary adenylate cyclase activating polypeptide in mouse microglial cells," Journal of Neuroscience Research, vol. 51, no. 3, pp. 382-390, 1998.

[101] W.-K. Kim, D. Ganea, and G. M. Jonakait, "Inhibition of microglial CD40 expression by pituitary adenylate cyclaseactivating polypeptide is mediated by interleukin-10," Journal of Neuroimmunology, vol. 126, no. 1-2, pp. 16-24, 2002.

[102] W.-K. Kim, Y. Kan, D. Ganea, R. P. Hart, I. Gozes, and G. M. Jonakait, "Vasoactive intestinal peptide and pituitary adenylyl cyclase-activating polypeptide inhibit tumor necrosis factor- $\alpha$ production in injured spinal cord and in activated microglia via a cAMP-dependent pathway," Journal of Neuroscience, vol. 20, no. 10, pp. 3622-3630, 2000.

[103] M. Delgado, G. M. Jonakait, and D. Ganea, "Vasoactive intestinal peptide and pituitary adenylate cyclase-activating polypeptide inhibit chemokine production in activated microglia," Glia, vol. 39, no. 2, pp. 148-161, 2002.

[104] M. Delgado, J. Leceta, and D. Ganea, "Vasoactive intestinal peptide and pituitary adenylate cyclase-activating polypeptide inhibit the production of inflammatory mediators by activated microglia," Journal of Leukocyte Biology, vol. 73, no. 1, pp. 155164, 2003.

[105] M. Delgado, "Vasoactive intestinal peptide and pituitary adenylate cyclase-activating polypeptide inhibit the MEKK1/MEK4/ JNK signaling pathway in endotoxin-activated microglia," Biochemical and Biophysical Research Communications, vol. 293, no. 2, pp. 771-776, 2002.

[106] M. Delgado, "Vasoactive intestinal peptide and pituitary adenylate cyclase-activating polypeptide inhibit CBP-NF- $\kappa \mathrm{B}$ interaction in activated microglia," Biochemical and Biophysical Research Communications, vol. 297, no. 5, pp. 1181-1185, 2002.

[107] M. Nishimoto, H. Miyakawa, K. Wada, and A. Furuta, "Activation of the VIP/VPAC2 system induces reactive astrocytosis associated with increased expression of glutamate transporters," Brain Research, vol. 1383, pp. 43-53, 2011.

[108] M. Delgado and D. Ganea, "Vasoactive intestinal peptide prevents activated microglia-induced neurodegeneration under inflammatory conditions: potential therapeutic role in brain trauma," The FASEB Journal, vol. 17, no. 13, pp. 1922-1924, 2003.

[109] M. Delgado and D. Ganea, "Neuroprotective effect of vasoactive intestinal peptide (VIP) in a mouse model of Parkinson's disease 
by blocking microglial activation," The FASEB Journal, vol. 17, no. 8, pp. 944-946, 2003.

[110] M. Song, J.-X. Xiong, Y.-Y. Wang, J. Tang, B. Zhang, and Y. Bai, "VIP enhances phagocytosis of fibrillar beta-amyloid by microglia and attenuates amyloid deposition in the brain of APP/PS1 mice," PLoS ONE, vol. 7, no. 2, Article ID e29790, 2012.

[111] R. P. Gomariz, I. Gutiérrez-Cañas, A. Arranz et al., "Peptides targeting toll-like receptor signalling pathways for novel immune therapeutics," Current Pharmaceutical Design, vol. 16, no. 9, pp. 1063-1080, 2010.

[112] R. P. Gomariz, A. Arranz, C. Abad et al., "Time-course expression of Toll-like receptors 2 and 4 in inflammatory bowel disease and homeostatic effect of VIP," Journal of Leukocyte Biology, vol. 78, no. 2, pp. 491-502, 2005.

[113] N. Foster, S. R. Lea, P. M. Preshaw, and J. J. Taylor, "Pivotal advance: vasoactive intestinal peptide inhibits up-regulation of human monocyte TLR 2 and TLR 4 by LPS and differentiation of monocytes to macrophages," Journal of Leukocyte Biology, vol. 81, no. 4, pp. 893-903, 2007.

[114] X. Jiang, S. A. McClellan, R. P. Barrett, Y. Zhang, and L. D. Hazlett, "Vasoactive intestinal peptide downregulates proinflammatory TLRs while upregulating anti-inflammatory TLRs in the infected cornea," Journal of Immunology, vol. 189, no. 1, pp. 269-278, 2012.

[115] I. Gutiérrez-Cañas, Y. Juarranz, B. Santiago et al., "VIP downregulates TLR4 expression and TLR4-mediated chemokine production in human rheumatoid synovial fibroblasts," Rheumatology, vol. 45, no. 5, pp. 527-532, 2006.

[116] D. Offen, Y. Sherki, E. Melamed, M. Fridkin, D. E. Brenneman, and I. Gozes, "Vasoactive intestinal peptide (VIP) prevents neurotoxicity in neuronal cultures: relevance to neuroprotection in Parkinson's disease," Brain Research, vol. 854, no. 1-2, pp. 257$262,2000$.

[117] N. Fujimori, T. Oono, H. Igarashi et al., "Vasoactive intestinal peptide reduces oxidative stress in pancreatic acinar cells through the inhibition of NADPH oxidase," Peptides, vol. 32, no. 10, pp. 2067-2076, 2011.

[118] E. Vacas, A. M. Bajo, A. V. Schally, M. Sánchez-Chapado, J. C. Prieto, and M. J. Carmena, "Antioxidant activity of vasoactive intestinal peptide in HK2 human renal cells," Peptides, vol. 38, no. 2, pp. 275-281, 2012.

[119] R. Yu, H. Zhang, L. Huang, X. Liu, and J. Chen, "Antihyperglycemic, antioxidant and anti-inflammatory effects of VIP and a VPAC1 agonist on streptozotocin-induced diabetic mice," Peptides, vol. 32, no. 2, pp. 216-222, 2011.

[120] N. Tunçel, O. T. Korkmaz, N. Tekin, E. Şener, F. Akyüz, and M. Inal, "Antioxidant and anti-apoptotic activity of Vasoactive Intestinal Peptide (VIP) against 6-hydroxy dopamine toxicity in the rat corpus striatum," Journal of Molecular Neuroscience, vol. 46, no. 1, pp. 51-57, 2012.

[121] L. Mester, K. Kovacs, B. Racz et al., "Pituitary adenylate cyclaseactivating polypeptide is protective against oxidative stress in human retinal pigment epithelial cells," Journal of Molecular Neuroscience, vol. 43, no. 1, pp. 35-43, 2011.

[122] G. Horvath, R. Brubel, K. Kovacs et al., "Effects of PACAP on oxidative stress-induced cell death in rat kidney and human hepatocyte cells," Journal of Molecular Neuroscience, vol. 43, no. 1, pp. 67-75, 2011.

[123] O. Masmoudi-Kouki, S. Douiri, Y. Hamdi et al., "Pituitary adenylate cyclase-activating polypeptide protects astroglial cells against oxidative stress-induced apoptosis," Journal of Neurochemistry, vol. 117, no. 3, pp. 403-411, 2011.
[124] H. Ohtaki, A. Satoh, T. Nakamachi et al., "Regulation of oxidative stress by pituitary adenylate cyclase-activating polypeptide (PACAP) mediated by PACAP receptor," Journal of Molecular Neuroscience, vol. 42, no. 3, pp. 397-403, 2010.

[125] P. Szakaly, E. Laszlo, K. Kovacs et al., "Mice deficient in pituitary adenylate cyclase activating polypeptide (PACAP) show increased susceptibility to in vivo renal ischemia/reperfusion injury," Neuropeptides, vol. 45, no. 2, pp. 113-121, 2011.

[126] R. A. Stetler, Y. Gao, R. S. Zukin et al., "Apurinic/apyrimidinic endonuclease APE1 is required for PACAP-induced neuroprotection against global cerebral ischemia," Proceedings of the National Academy of Sciences of the United States of America, vol. 107, no. 7, pp. 3204-3209, 2010.

[127] D. M. Basso, M. S. Beattie, and J. C. Bresnahan, "Graded histological and locomotor outcomes after spinal cord contusion using the NYU weight-drop device versus transection," Experimental Neurology, vol. 139, no. 2, pp. 244-256, 1996.

[128] K.-M. Fang, J.-K. Chen, S.-C. Hung et al., "Effects of combinatorial treatment with pituitary adenylate cyclase activating peptide and human mesenchymal stem cells on spinal cord tissue repair," PLoS ONE, vol. 5, no. 12, Article ID e15299, 2010.

[129] C. Brifault, M. Gras, D. Liot, V. May, D. Vaudry, and O. Wurtz, "Delayed pituitary adenylate cyclase-activating polypeptide delivery after brain stroke improves functional recovery by inducing M2 microglia/macrophage polarization," Stroke, vol. 46, no. 2, pp. 520-528, 2014.

[130] T. Nakamachi, M. Tsuchida, N. Kagami et al., "IL-6 and PACAP receptor expression and localization after global brain ischemia in mice," Journal of Molecular Neuroscience, vol. 48, no. 3, pp. 518-525, 2012.

[131] R. Nunan, H. Sivasathiaseelan, D. Khan, M. Zaben, and W. Gray, "Microglial VPAC1R mediates a novel mechanism of neuroimmune-modulation of hippocampal precursor cells via IL-4 release," Glia, vol. 62, no. 8, pp. 1313-1327, 2014.

[132] F. A. Russell, "Calcitonin gene-related peptide: physiology and pathophysiology," Physiological Reviews, vol. 94, no. 4, pp. 10991142, 2014.

[133] D. R. Poyner, P. M. Sexton, I. Marshall et al., "International Union of Pharmacology. XXXII. The mammalian calcitonin gene-related peptides, adrenomedullin, amylin, and calcitonin receptors," Pharmacological Reviews, vol. 54, no. 2, pp. 233-246, 2002.

[134] L. M. McLatchie, N. J. Fraser, M. J. Main et al., "RAMPS regulate the transport and ligand specificity of the calcitonin- receptorlike receptor," Nature, vol. 393, no. 6683, pp. 333-339, 1998.

[135] B. N. Evans, M. I. Rosenblatt, L. O. Mnayer, K. R. Oliver, and I. M. Dickerson, "CGRP-RCP, a novel protein required for signal transduction at calcitonin gene-related peptide and adrenomedullin receptors," The Journal of Biological Chemistry, vol. 275, no. 40, pp. 31438-31443, 2000.

[136] S. C. Egea and I. M. Dickerson, "Direct interactions between calcitonin-like receptor (CLR) and CGRP-receptor component protein (RCP) regulate CGRP receptor signaling," Endocrinology, vol. 153, no. 4, pp. 1850-1860, 2012.

[137] D. L. Hay, D. R. Poyner, and D. M. Smith, "Desensitisation of adrenomedullin and CGRP receptors," Regulatory Peptides, vol. 112, no. 1-3, pp. 139-145, 2003.

[138] S. D. Brain and A. D. Grant, "Vascular actions of calcitonin gene-related peptide and adrenomedullin," Physiological Reviews, vol. 84, no. 3, pp. 903-934, 2004.

[139] H. Drissi, F. Lasmoles, V. L. Mellay, P. J. Marie, and M. Lieberherr, "Activation of phospholipase C- $\beta 1$ via $\mathrm{G} \alpha(\mathrm{q} / 11)$ during 
calcium mobilization by calcitonin gene-related peptide," The Journal of Biological Chemistry, vol. 273, no. 32, pp. 20168-20174, 1998.

[140] H. Drissi, M. Lieberherr, M. Hott, P. J. Marie, and F. Lasmoles, "Calcitonin gene-related peptide (CGRP) increases intracellular free $\mathrm{Ca}^{2+}$ concentrations but not cyclic AMP formation in CGRP receptor-positive osteosarcoma cells (OHS-4)," Cytokine, vol. 11, no. 3, pp. 200-207, 1999.

[141] S. Morara, L.-P. Wang, V. Filippov et al., "Calcitonin generelated peptide (CGRP) triggers $\mathrm{Ca}^{2+}$ responses in cultured astrocytes and in Bergmann glial cells from cerebellar slices," European Journal of Neuroscience, vol. 28, no. 11, pp. 2213-2220, 2008.

[142] Z. Wang, W. Ma, J.-G. Chabot, and R. Quirion, "Calcitonin gene-related peptide as a regulator of neuronal CaMKII-CREB, microglial p38-NF $\kappa$ B and astroglial ERK-Stat1/3 cascades mediating the development of tolerance to morphine-induced analgesia," Pain, vol. 151, no. 1, pp. 194-205, 2010.

[143] M. E. Bigal, S. Walter, and A. M. Rapoport, "Calcitonin generelated peptide (CGRP) and migraine current understanding and state of development," Headache, vol. 53, no. 8, pp. 12301244, 2013.

[144] S. Evangelista, "Role of calcitonin gene-related peptide in gastric mucosal defence and healing," Current Pharmaceutical Design, vol. 15, no. 30, pp. 3571-3576, 2009.

[145] A. Dakhama, G. L. Larsen, and E. W. Gelfand, "Calcitonin generelated peptide: role in airway homeostasis," Current Opinion in Pharmacology, vol. 4, no. 3, pp. 215-220, 2004.

[146] A.-G. Lafont, Y.-F. Wang, G.-D. Chen et al., "Involvement of calcitonin and its receptor in the control of calcium-regulating genes and calcium homeostasis in zebrafish (Danio rerio)," Journal of Bone and Mineral Research, vol. 26, no. 5, pp. 10721083, 2011.

[147] P. Holzer, "Neurogenic vasodilatation and plasma leakage in the skin," General Pharmacology, vol. 30, no. 1, pp. 5-11, 1998.

[148] A. C. Raddant and A. F. Russo, "Calcitonin gene-related peptide in migraine: intersection of peripheral inflammation and central modulation," Expert Reviews in Molecular Medicine, vol. 13, article e36, 2011.

[149] R. N. Gomes, H. C. Castro-Faria-Neto, P. T. Bozza et al., "Calcitonin gene-related peptide inhibits local acute inflammation and protects mice against lethal endotoxemia," Shock, vol. 24, no. 6, pp. 590-594, 2005.

[150] I. Kroeger, A. Erhardt, D. Abt et al., "The neuropeptide calcitonin gene-related peptide (CGRP) prevents inflammatory liver injury in mice," Journal of Hepatology, vol. 51, no. 2, pp. 342-353, 2009.

[151] M. Levite, "Neuropeptides, by direct interaction with T cells, induce cytokine secretion and break the commitment to a distinct T helper phenotype," Proceedings of the National Academy of Sciences of the United States of America, vol. 95, no. 21, pp. 12544-12549, 1998.

[152] Y. Umeda, M. Takamiya, H. Yoshizaki, and M. Arisawa, "Inhibition of mitogen-stimulated $\mathrm{T}$ lymphocyte proliferation by calcitonin gene-related peptide," Biochemical and Biophysical Research Communications, vol. 154, no. 1, pp. 227-235, 1988.

[153] J. P. McGillis, S. Humphreys, V. Rangnekar, and J. Ciallella, "Modulation of B lymphocyte differentiation by calcitonin gene-related peptide (CGRP). II. Inhibition of LPS-induced kappa light chain expression by CGRP,' Cellular Immunology, vol. 150, no. 2, pp. 405-416, 1993.
[154] S. Fernandez, M. A. Knopf, and J. P. McGillis, "Calcitonin-gene related peptide (CGRP)inhibits interleukin-7-induced pre-B cell colony formation," Journal of Leukocyte Biology, vol. 67, no. 5, pp. 669-676, 2000.

[155] W. Ding, L. L. Stohl, J. A. Wagner, and R. D. Granstein, "Calcitonin gene-related peptide biases langerhans cells toward Th2-type immunity," The Journal of Immunology, vol. 181, no. 9, pp. 6020-6026, 2008.

[156] M. Baliu-Piqué, G. Jusek, and B. Holzmann, "Neuroimmunological communication via CGRP promotes the development of a regulatory phenotype in TLR4-stimulated macrophages," European Journal of Immunology, vol. 44, no. 12, pp. 3708-3716, 2014.

[157] A. Consonni, S. Morara, F. Codazzi, F. Grohovaz, and D. Zacchetti, "Inhibition of lipopolysaccharide-induced microglia activation by calcitonin gene related peptide and adrenomedullin," Molecular and Cellular Neuroscience, vol. 48, no. 2, pp. 151-160, 2011.

[158] H. Li, M. L. Cuzner, and J. Newcombe, "Microglia-derived macrophages in early multiple sclerosis plaques," Neuropathology and Applied Neurobiology, vol. 22, no. 3, pp. 207-215, 1996.

[159] F. W. Gay, T. J. Drye, G. W. A. Dick, and M. M. Esiri, “The application of multifactorial cluster analysis in the staging of plaques in early multiple sclerosis: identification and characterization of the primary demyelinating lesion," Brain, vol. 120, no. 8, pp. 1461-1483, 1997.

[160] C. Trebst, T. Lykke Sørensen, P. Kivisäkk et al., "CCR1 ${ }^{+} /$CCR $^{+}$ mononuclear phagocytes accumulate in the central nervous system of patients with multiple sclerosis," The American Journal of Pathology, vol. 159, no. 5, pp. 1701-1710, 2001.

[161] M. M. Ayers, L. J. Hazelwood, D. V. Catmull et al., "Early glial responses in murine models of multiple sclerosis," Neurochemistry International, vol. 45, no. 2-3, pp. 409-419, 2004.

[162] M. D. Harzenetter, A. R. Novotny, P. Gais, C. A. Molina, F. Altmayr, and B. Holzmann, "Negative regulation of TLR responses by the neuropeptide CGRP is mediated by the transcriptional repressor ICER," The Journal of Immunology, vol. 179, no. 1, pp. 607-615, 2007.

[163] C. Schaeffer, D. Vandroux, L. Thomassin, P. Athias, L. Rochette, and J.-L. Connat, "Calcitonin gene-related peptide partly protects cultured smooth muscle cells from apoptosis induced by an oxidative stress via activation of ERK1/2 MAPK," Biochimica et Biophysica Acta-Molecular Cell Research, vol. 1643, no. 1-3, pp. 65-73, 2003.

[164] S. Sueur, M. Pesant, L. Rochette, and J.-L. Connat, "Antiapoptotic effect of calcitonin gene-related peptide on oxidative stress-induced injury in $\mathrm{H} 9 \mathrm{c} 2$ cardiomyocytes via the RAMP1/CRLR complex," Journal of Molecular and Cellular Cardiology, vol. 39, no. 6, pp. 955-963, 2005.

[165] Z. Zhou, C.-P. Hu, C.-J. Wang, T.-T. Li, J. Peng, and Y.-J. $\mathrm{Li}$, "Calcitonin gene-related peptide inhibits angiotensin IIinduced endothelial progenitor cells senescence through upregulation of klotho expression," Atherosclerosis, vol. 213, no. 1, pp. 92-101, 2010.

[166] N. A. Umoh, R. K. Walker, R. M. Millis et al., "Calcitonin gene-related peptide regulates cardiomyocyte survival through regulation of oxidative stress by PI3K/Akt and MAPK signaling pathways," Annals of Clinical and Experimental Hypertension, vol. 2, no. 1, pp. 1007-1023, 2014.

[167] R. Huang, A. Karve, I. Shah et al., "Deletion of the mouse $\alpha$ calcitonin gene-related peptide gene increases the vulnerability of the heart to ischemia-reperfusion injury," American Journal 
of Physiology-Heart and Circulatory Physiology, vol. 294, no. 3, pp. H1291-H1297, 2008.

[168] L. Yang, T. Sakurai, A. Kamiyoshi et al., "Endogenous CGRP protects against neointimal hyperplasia following wire-induced vascular injury," Journal of Molecular and Cellular Cardiology, vol. 59, pp. 55-66, 2013.

[169] S.-J. Smillie, R. King, X. Kodji et al., "An ongoing role of $\alpha$ calcitonin gene-related peptide as part of a protective network against hypertension, vascular hypertrophy, and oxidative stress," Hypertension, vol. 63, no. 5, pp. 1056-1062, 2014.

[170] S. Hinuma, H. Onda, and M. Fujino, "The quest for novel bioactive peptides utilizing orphan seven-transmembrane-domain receptors," Journal of Molecular Medicine, vol. 77, no. 6, pp. 495504, 1999.

[171] Y. Habata, R. Fujii, M. Hosoya et al., "Apelin, the natural ligand of the orphan receptor APJ, is abundantly secreted in the colostrum," Biochimica et Biophysica Acta, vol. 1452, no. 1, pp. 25-35, 1999.

[172] M. Hosoya, Y. Kawamata, S. Fukusumi et al., "Molecular and functional characteristics of APJ. Tissue distribution of mRNA and interaction with the endogenous ligand apelin," The Journal of Biological Chemistry, vol. 275, no. 28, pp. 21061-21067, 2000.

[173] B. Masri, B. Knibiehler, and Y. Audigier, "Apelin signalling: a promising pathway from cloning to pharmacology," Cellular Signalling, vol. 17, no. 4, pp. 415-426, 2005.

[174] N. De Mota, Z. Lenkei, and C. Llorens-Cortès, "Cloning, pharmacological characterization and brain distribution of the rat apelin receptor," Neuroendocrinology, vol. 72, no. 6, pp. 400$407,2000$.

[175] A.-M. O'Carroll, T. L. Selby, M. Palkovits, and S. J. Lolait, "Distribution of mRNA encoding B78/apj, the rat homologue of the human APJ receptor, and its endogenous ligand apelin in brain and peripheral tissues," Biochimica et Biophysica ActaGene Structure and Expression, vol. 1492, no. 1, pp. 72-80, 2000.

[176] E. Devic, L. Paquereau, P. Vernier, B. Knibiehler, and Y. Audigier, "Expression of a new G protein-coupled receptor Xmsr is associated with an endothelial lineage in Xenopus laevis," Mechanisms of Development, vol. 59, no. 2, pp. 129-140, 1996.

[177] S. D. Katugampola, J. J. Maguire, S. R. Matthewson, and A. P. Davenport, "[ $\left.{ }^{125} \mathrm{I}\right]-\left(\mathrm{Pyr}^{1}\right)$ Apelin-13 is a novel radioligand for localizing the APJ orphan receptor in human and rat tissues with evidence for a vasoconstrictor role in man," British Journal of Pharmacology, vol. 132, no. 6, pp. 1255-1260, 2001.

[178] H. Choe, M. Farzan, M. Konkel et al., "The orphan seventransmembrane receptor Apj supports the entry of primary Tcell-line-tropic and dualtropic human immunodeficiency virus type 1," Journal of Virology, vol. 72, no. 7, pp. 6113-6118, 1998.

[179] A. Folino, P. G. Montarolo, M. Samaja, and R. Rastaldo, "Effects of apelin on the cardiovascular system," Heart Failure Reviews, vol. 20, no. 4, pp. 505-518, 2015.

[180] Y. Yang, S.-Y. Lv, S.-K. Lyu, D. Wu, and Q. Chen, “The protective effect of apelin on ischemia/reperfusion injury," Peptides, vol. 63, pp. 43-46, 2015.

[181] J. Kim, "Apelin-APJ signaling: a potential therapeutic target for pulmonary arterial hypertension," Molecules and Cells, vol. 37, no. 3, pp. 196-201, 2014.

[182] S.-Y. Lv, Y.-J. Yang, and Q. Chen, "Regulation of feeding behavior, gastrointestinal function and fluid homeostasis by apelin," Peptides, vol. 44, pp. 87-92, 2013.

[183] W. Choe, A. Albright, J. Sulcove et al., "Functional expression of the seven-transmembrane HIV-1 co-receptor APJ in neural cells," Journal of NeuroVirology, vol. 6, no. 1, pp. S61-S69, 2000.
[184] B. Masri, H. Lahlou, H. Mazarguil, B. Knibiehler, and Y. Audigier, "Apelin (65-77) activates extracellular signalregulated kinases via a PTX-sensitive G protein," Biochemical and Biophysical Research Communications, vol. 290, no. 1, pp. 539-545, 2002.

[185] Q. Xin, B. Cheng, Y. Pan et al., "Neuroprotective effects of apelin-13 on experimental ischemic stroke through suppression of inflammation," Peptides, vol. 63, pp. 55-62, 2015.

[186] O. Pisarenko, V. Shulzhenko, I. Studneva et al., "Structural apelin analogues: mitochondrial ROS inhibition and cardiometabolic protection in myocardial ischaemia reperfusion injury," British Journal of Pharmacology, vol. 172, no. 12, pp. 2933-2945, 2015.

[187] E. Thornton and R. Vink, "Treatment with a substance p receptor antagonist is neuroprotective in the intrastriatal 6hydroxydopamine model of early parkinson's disease," PLoS ONE, vol. 7, no. 4, Article ID e34138, 2012. 

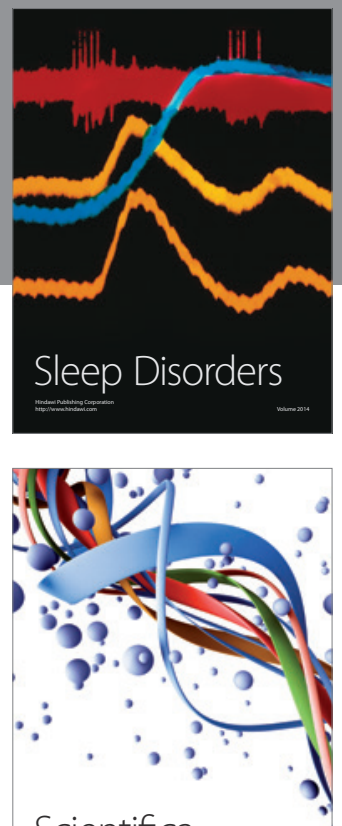

Scientifica
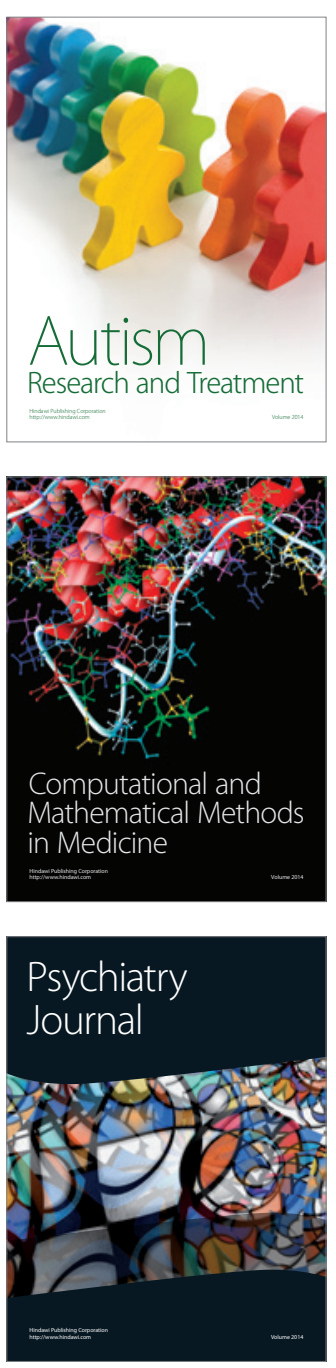
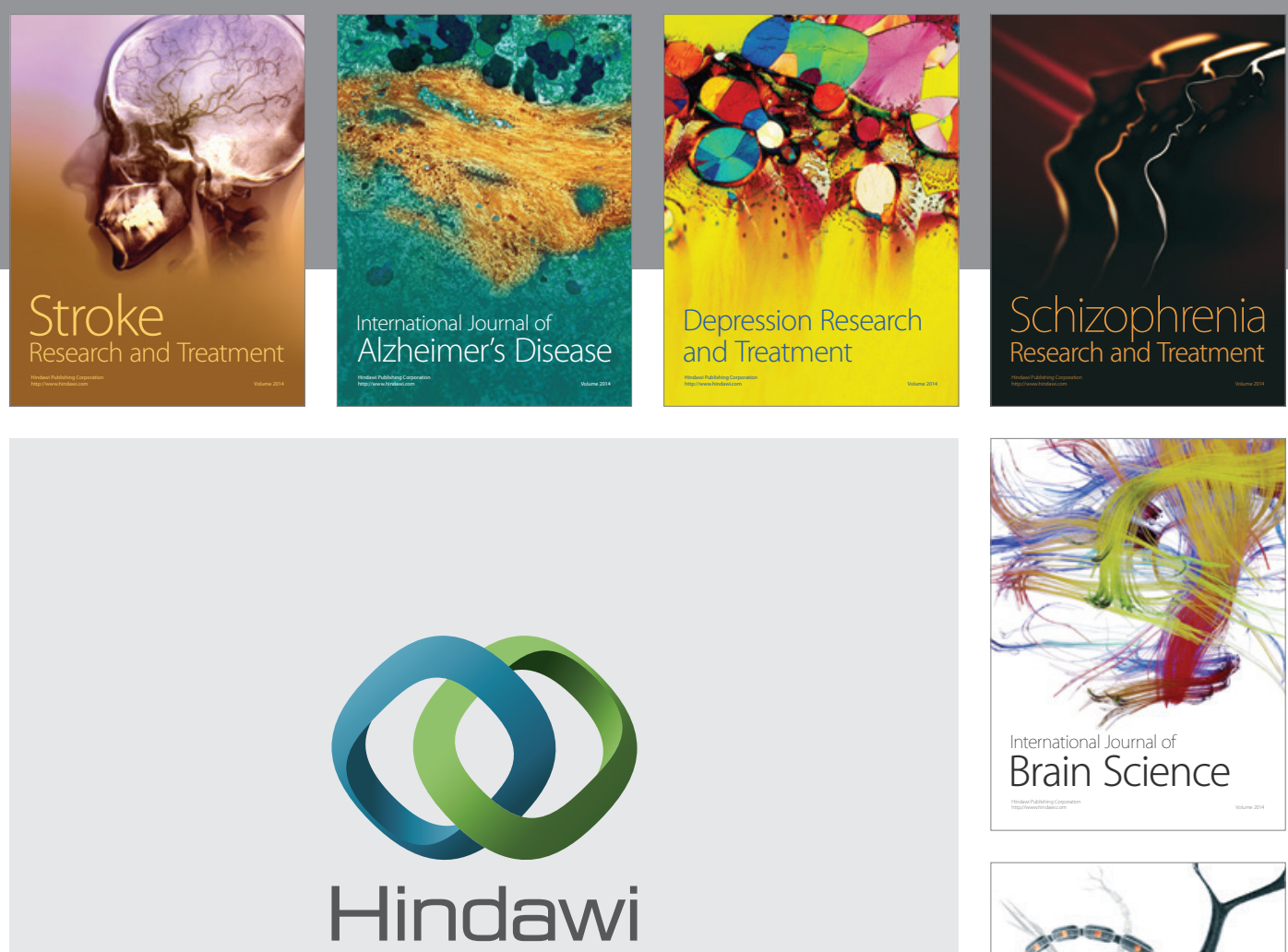

Submit your manuscripts at

http://www.hindawi.com
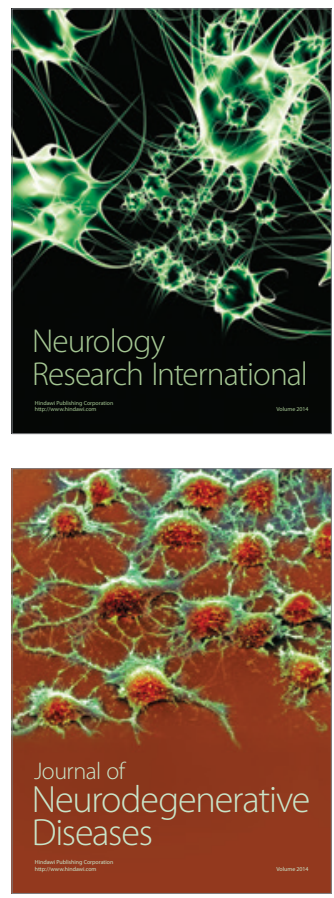

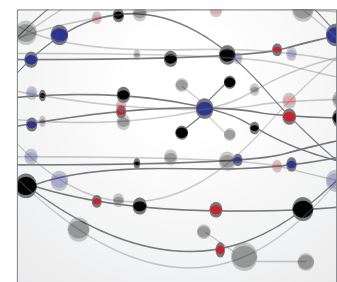

The Scientific World Journal
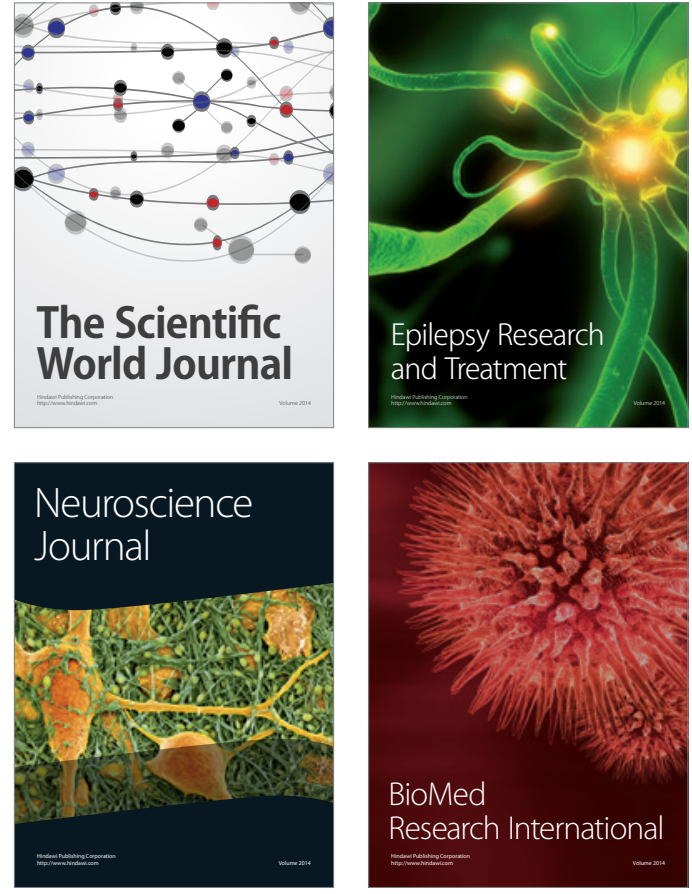

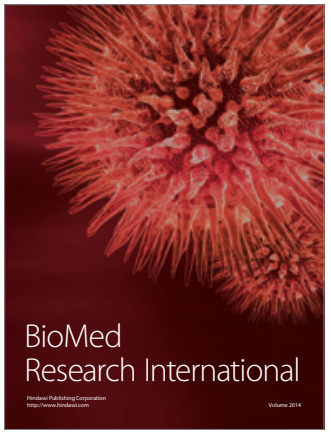

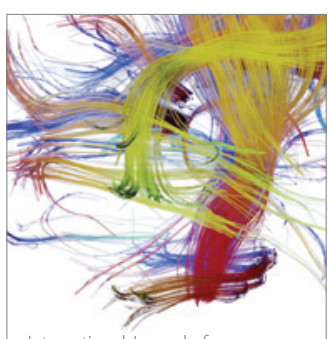

Brain Science

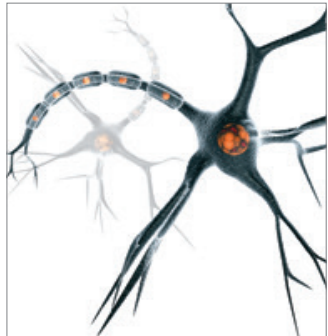

Neural Plasticity
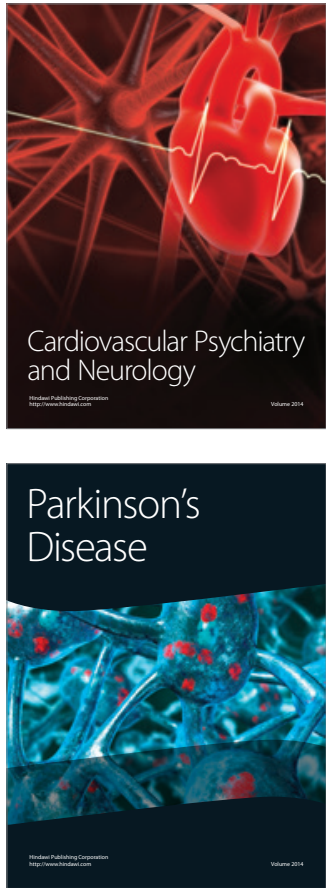